\title{
A Self-Organizing-Map-Based Evaluation of the Antarctic Mesoscale Prediction System Using Observations from a 30-m Instrumented Tower on the Ross Ice Shelf, Antarctica
}

\author{
Melissa A. Nigro And John J. CASSANO \\ Cooperative Institute for Research in Environmental Sciences, and Department of Atmospheric \\ and Oceanic Sciences, University of Colorado Boulder, Boulder, Colorado \\ JONATHAN WILLE \\ Polar Meteorology Group, Byrd Polar and Climate Research Center, The Ohio State University, Columbus, Ohio
}

\section{DAVID H. BROMWICH}

Polar Meteorology Group, Byrd Polar and Climate Research Center, and Atmospheric Sciences Program, Department of Geography, The Ohio State University, Columbus, Ohio

MATTHEW A. LAZZARA

Antarctic Meteorological Research Center, Space Science and Engineering Center, University of Wisconsin-Madison, and Department of Physical Sciences, School of Arts and Sciences, Madison Area Technical College, Madison, Wisconsin

(Manuscript received 29 April 2016, in final form 17 November 2016)

\begin{abstract}
Accurate representation of the stability of the surface layer in numerical weather prediction models is important because of the impact it has on forecasts of surface energy, moisture, and momentum fluxes. It also impacts boundary layer processes such as the generation of turbulence, the creation of near-surface flows, and fog formation. This paper uses observations from a 30-m automatic weather station on the Ross Ice Shelf, Antarctica, to evaluate the near-surface layer in the Antarctic Mesoscale Prediction System (AMPS), a numerical weather prediction system used for forecasting in Antarctica. The method of self-organizing maps (SOM) is used to identify characteristic potential temperature anomaly profiles observed at the $30-\mathrm{m}$ tower. The SOMidentified profiles are then used to evaluate the performance of AMPS as a function of atmospheric stability.

The results indicate AMPS underpredicts the frequency of near-neutral profiles and instead overpredicts the frequency of weakly unstable and weak to moderately stable profiles. AMPS does not forecast the strongest statically stable patterns observed by Tall Tower, but in the median, the AMPS forecasts are more statically stable across all wind speeds, indicating a possible mechanical mixing error or a negative radiation bias. The SOM analysis identifies a negative radiation bias under near-neutral to weakly stable conditions, causing an overrepresentation of the static stability in AMPS. AMPS has a positive wind speed bias in moderate to strongly stable conditions, which generates too much mechanical mixing and an underrepresentation of the static stability. Model errors increase with increasing atmospheric stability.
\end{abstract}

Supplemental information related to this paper is available at the Journals Online website: http://dx.doi.org/10.1175/ WAF-D-16-0084.s1.

Byrd Polar and Climate Research Center Contribution Number 1559.

Corresponding author e-mail: Melissa A. Nigro, melissa.nigro@ colorado.edu

\section{Introduction}

Accurate representation of the stability of the surface layer in numerical weather prediction (NWP) models is important since this impacts forecasts of surface energy, moisture, and momentum fluxes. It also impacts boundary layer processes such as the generation of turbulence, the creation of near-surface flows (i.e., katabatic winds and barrier winds), and fog formation. 
The surface layer over Antarctica differs from the surface layer in most regions of the world. The permanent snow and ice surfaces in Antarctica result in radiational cooling and downward-directed turbulent heat fluxes over much of the year that create persistent statically stable surface layers and frequent surface inversions (King and Turner 1997). Previous studies have used observations to evaluate the frequency of statically stable surface layers and the strength of the vertical temperature gradient for various places around the Antarctic. Observations from Antarctica show statically stable surface layers occurring approximately $83 \%$ of the time over the Ross Ice Shelf (RIS) (Cassano et al. 2016), $74 \%$ of the time in the summer and $92 \%$ of the time in the winter at South Pole Station (Hudson and Brandt 2005), $85 \%$ of the time at Dome Concordia (Genthon et al. 2013), 70\% of the time at Dome A (Hu et al. 2014), and throughout the year at Plateau Station (Riordan 1977). The maximum vertical potential temperature gradient observed at a 30-m tower located on the RIS was $0.9^{\circ} \mathrm{Cm}^{-1}$ (Cassano et al. 2016) while the maximum vertical temperature gradient observed by the $45-\mathrm{m}$ tower at Dome $\mathrm{C}$ over the interior of the continent was $2.5^{\circ} \mathrm{Cm}^{-1}$ (Genthon et al. 2013).

Previous studies have highlighted some of the difficulties in accurately simulating stable boundary layers in NWP models (e.g., Derbyshire 1999; Poulos and Burns 2003; Tjernstrom et al. 2004; Brunke et al. 2006; Holtslag 2006; Steeneveld et al. 2006; Banta et al. 2007; Teixeira et al. 2008; Baklanov et al. 2011; Atlaskin and Vihma 2012; Rinke et al. 2012; Holtslag et al. 2013; Kleczek et al. 2014; Sterk et al. 2015) and specifically over the RIS (Steinhoff et al. 2009; Wille et al. 2016). One challenge associated with simulating stable boundary layers is adequate vertical resolution in the often shallow stable boundary layer (King and Turner 1997; Tjernstrom et al. 2004; Banta et al. 2007). In recent years, the nearsurface vertical resolution has increased in NWP models, but additional knowledge of smaller-scale processes is required to adapt the current planetary boundary layer (PBL) and surface-layer parameterizations to the higher vertical resolution models (Teixeira et al. 2008; Baklanov et al. 2011).

A wide range of model errors exists with respect to simulating stable boundary layers. A common model error is the underrepresentation of the near-surface vertical temperature gradient, or an underrepresentation of the static stability (Atlaskin and Vihma 2012; Sterk et al. 2015). This is often a reflection of the PBL parameterization generating too much mechanical mixing to avoid decoupling of the atmosphere from the surface (Derbyshire 1999; Poulos and Burns 2003; Holtslag 2006; Rinke et al. 2012; Holtslag et al. 2013). This also occurs when there is a positive wind speed bias and the mechanical mixing generated by the strong winds in the model decreases the near-surface stability (Tjernstrom et al. 2004; Wille et al. 2016). On the other end of the spectrum, some NWP models underpredict the low-level wind speeds, generating too little mechanical mixing, resulting in an overprediction of the static stability and a cold bias in the surface temperature (Steinhoff et al. 2009). Also impacting the model forecasts of atmospheric stability is the model representation of the energy budget, which is impacted by processes such as cloud cover, moisture content, surface radiative and turbulent fluxes, and temperature advection (Tjernstrom et al. 2004; Brunke et al. 2006; Steeneveld et al. 2006). The complexities involved with simulating stable boundary layers emphasize the need for PBL observations and an evaluation of current PBL and surface-layer parameterizations (Baklanov et al. 2011).

This study uses observations from a 30-m instrumented tower on the RIS to assess the ability of the Antarctic Mesoscale Prediction System (AMPS) to simulate the near-surface stability and associated wind and temperature profiles. AMPS is a real-time NWP system used by the U.S. Antarctic Program (USAP) to provide forecasts for Antarctic flight operations and logistical activity around the continent. Therefore, accurate forecasts are critical to the safety of those working in Antarctica (Powers et al. 2012). The AMPS forecast archive is also used for research purposes, where accurate forecasts are important for diagnosing the behavior of the atmosphere (Schlosser et al. 2008; Steinhoff et al. 2009; Speirs et al. 2010; Bromwich et al. 2011; Nicolas and Bromwich 2011; Seefeldt and Cassano 2012; Nigro and Cassano 2014a).

Observations from the Alexander Tall Tower! automatic weather station (AWS, henceforth the Tall Tower AWS or simply the Tall Tower; Lazzara et al. 2012; Cassano et al. 2016; Wille et al. 2016) will be used to evaluate the stability of the surface layer in AMPS. We note that our use of the term surface layer refers to the bottom $30 \mathrm{~m}$ of the atmosphere, even though during strong stable conditions the surface layer is likely to be shallower than this (Cassano et al. 2016). The Tall Tower AWS is a $30-\mathrm{m}$ instrumented tower located on the RIS $\left(79.044^{\circ} \mathrm{S}, 170.651^{\circ} \mathrm{E}\right.$; see Fig. 1). It has six levels of instrumentation and observations are recorded at 10-s intervals. The Tall Tower AWS provides the first continuous set of vertical observations over the RIS, delivering the information necessary to analyze the surface layer in this region (Cassano et al. 2016).

This paper uses a combination of the Tall Tower AWS observations and the method of self-organizing maps (SOM) to evaluate the surface layer in AMPS over a range of stability patterns. The SOM method is advantageous for this analysis because the model errors likely 


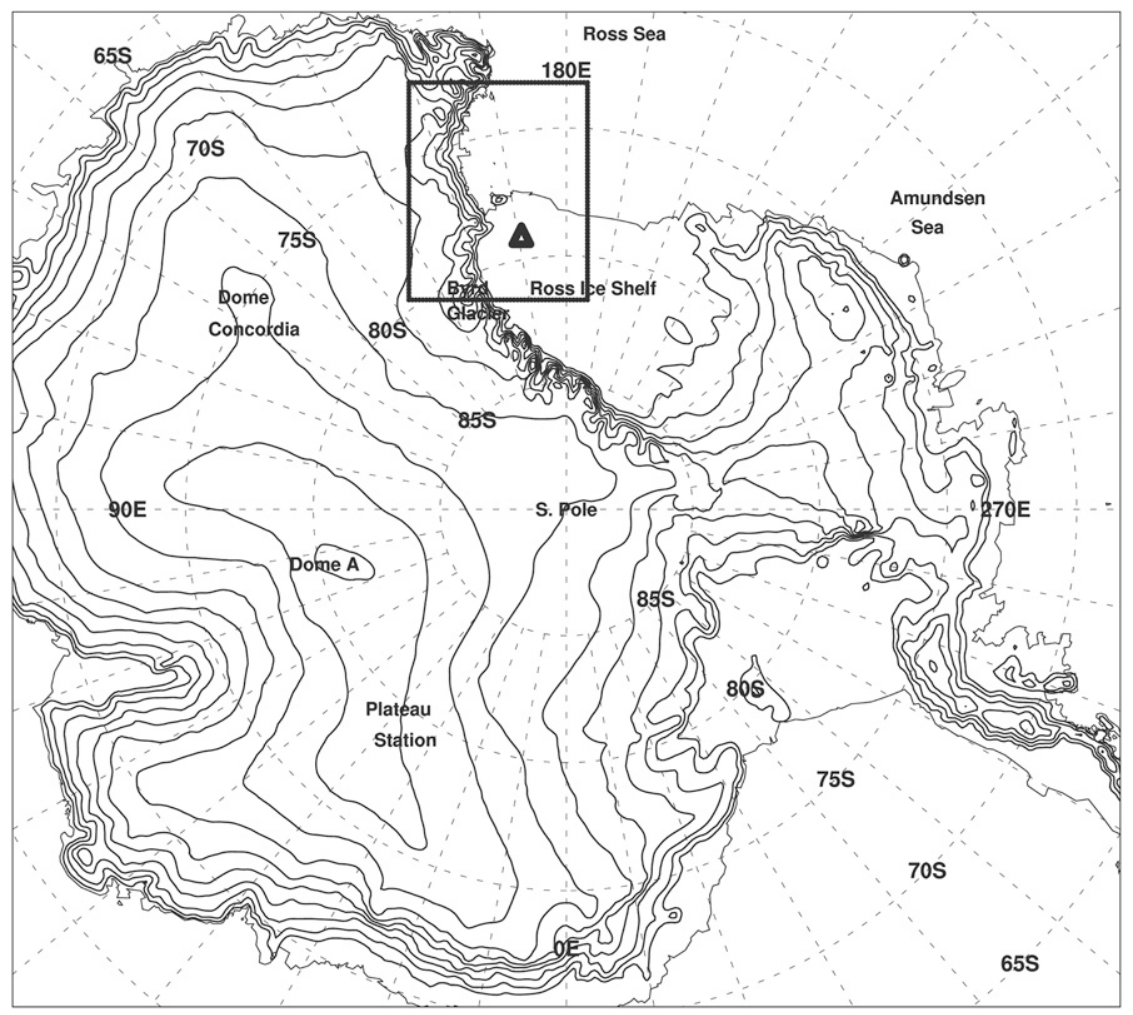

CONTOUR FROM 400 TO 4000 BY 400

FIG. 1. Map of Antarctica. Contour lines show elevation with a contour interval of $400 \mathrm{~m}$. The triangle indicates the location of the Tall Tower AWS. The black box indicates AMPS domain 3.

vary as a function of atmospheric stability. This type of analysis allows forecasters to tailor their forecasts based on the forecast stability and the stability-varying error identified with this analysis and is similar to the synopticpattern-based error identification presented in Nigro et al. (2011). Details about AMPS and the Tall Tower AWS observations are presented in section 2. Section 3 describes the methods used to interpolate the AMPS data to the heights of the Tall Tower observations, as well as the details involved with the SOM method. Section 4 presents the results of the study and concluding remarks and discussion are presented in section 5 .

\section{Data}

\section{a. Antarctic Mesoscale Prediction System}

AMPS is run by the National Center for Atmospheric Research (NCAR) to provide real-time weather forecasts for the USAP as well as other Antarctic national programs (Powers et al. 2012; http://www.mmm.ucar. edu/rt/wrf/amps). It is based on a polar-modified version of the Weather Research and Forecasting (Polar WRF) Model, which has been adapted to account for processes that are specific to the polar regions. These modifications include a scheme for fractional sea ice, an improved representation of heat transfer through snow and ice surfaces, a revised surface energy budget, and model physics options optimized for polar regions (Hines and Bromwich 2008; Bromwich et al. 2009; Hines et al. 2011; Bromwich et al. 2013; Hines et al. 2015). AMPS is run twice daily using first-guess initialization and lateral boundary conditions from the National Centers for Environmental Prediction $0.5^{\circ}$ Global Forecast System model output. Three-dimensional variational data assimilation is used to assimilate observations into AMPS. The AMPS output is archived and available through the Computational and Informational Systems Laboratory, a division of NCAR.

This study uses AMPS output from February 2011 through January 2013. The configuration of AMPS during this time period is described in Table 1. Of particular relevance for this work, the Mellor-YamadaJanjić (Eta) TKE-based PBL parameterization and the Monin-Obukhov (Janjić Eta) surface-layer scheme are used to represent the surface and boundary layer processes in the model. Output from AMPS domain 3 
TABLE 1. AMPS configuration.

\begin{tabular}{ll}
\hline \hline \multicolumn{1}{c}{ Category } & \multicolumn{1}{c}{ AMPS configuration } \\
\hline $\begin{array}{l}\text { Forecasting model } \\
\text { Longwave radiation }\end{array}$ & WRF 3.0.1.1 upgraded to WRF 3.2.1 on 27 Apr 2011 \\
Shortwave radiation & RRTM upgraded to RRTM with GCM applications (RRTMG) on 27 Apr 2011 (Mlawer et al. 1997) \\
Boundary layer & Goddard shortwave radiation scheme (Chou and Suarez 1994) \\
Surface-layer scheme & Mellor-Yamada-Janjić (Eta) TKE scheme (Janjić 1990, 1996, 2002) \\
Land surface option & Monin-Obukhov (Janjić Eta) scheme (Janjić 1996; 2002; Monin and Obukhov 1954) \\
Microphysics & Unified Noah LSM (Chen and Dudhia 2001) \\
Cumulus parameterization & WSM 5-class scheme (Hong et al. 2004; Hong and Lim 2006) \\
Sea ice & Kain-Frisch (new Eta) parameterization; no cumulus parameterization (Kain 2004) \\
Model top & Implementation of fractional sea ice \\
\hline
\end{tabular}

(Fig. 1), which covers the northwestern RIS with horizontal grid spacing of $5 \mathrm{~km}$, is used here. AMPS uses terrain-following eta levels as the vertical coordinate system. The average heights of the lowest two eta levels are 12 and $31 \mathrm{~m}$ above the surface, placing the first eta level within the depth of the Tall Tower AWS and the second just above the tower. Domain 3 is run for $36 \mathrm{~h}$ with the output archived every hour. To allow the model sufficient time to spin up from the initial conditions, and following previous studies that have used AMPS (e.g., Bromwich et al. 2005; Seefeldt and Cassano 2008; Nigro and Cassano 2014a,b; Wille et al. 2016), the majority of the analysis in this study uses the 12-23-h forecasts. The exception to this is the statistical analysis of the model performance, which analyzes a range of forecast hours $(0-11,12-23$, and $24-35 \mathrm{~h})$ to evaluate how the model performance varies as a function of forecast duration.

\section{b. Tall Tower automatic weather station observations}

The AMPS output is evaluated using the February 2011-January 2013 Tall Tower AWS observations (Lazzara et al. 2012; Cassano et al. 2016; Wille et al. 2016). The Tall Tower AWS is a $30-\mathrm{m}$ instrumented tower installed on the RIS in February 2011. It is located in the northwestern portion of the RIS (Fig. 1) and is often in the path of the RIS airstream (Parish et al. 2006; Seefeldt and Cassano
2012; Nigro and Cassano 2014a,b) and the path of katabatic drainage from Byrd Glacier (Seefeldt et al. 2007; Seefeldt and Cassano 2008). The region is located at an elevation of approximately $58 \mathrm{~m}$ and receives approximately $0.5 \mathrm{~m}$ of snow accumulation per year. The AWS is outfitted with six levels of instrumentation. Details on the instruments, the average instrument height over the 2-yr period (Cassano et al. 2016), and the manufacturer-stated instrument accuracy are provided in Table 2. Additional information about the Tall Tower AWS is available online (http://amrc.ssec.wisc.edu).

The Tall Tower AWS data were manually quality controlled to remove erroneous measurements due to solar radiation errors, frozen wind instruments, and other instrument/measurement errors. The quality control process follows the method described in Cassano et al. (2016) and was applied to the raw instantaneous 10-min observations. To account for solar radiation errors (Genthon et al. 2011), temperature observations were manually analyzed if the temperature increased by more than $1{ }^{\circ} \mathrm{C}$ between two 10 -min observations, the wind speed was less than $3 \mathrm{~m} \mathrm{~s}^{-1}$, and the sun was above the horizon. In each of these instances, the temperature observations were removed from the dataset if the temperature increase was larger than the temperature variability of the day. Additionally, all temperature

TABLE 2. Tall Tower instruments, heights, and manufacturer-stated accuracy.

\begin{tabular}{|c|c|c|}
\hline Instrument & Height (m) & Manufacturer-stated accuracy \\
\hline R.M. Young platinum resistance temperature & $0.85,1.83,3.75,7.25,14.75$, and 29.75 & $\pm 0.3^{\circ} \mathrm{C}$ \\
\hline Vaisala HMP45C-L humidity & 7.25 and 29.75 & $\begin{array}{l} \pm 2 \%(0 \%-90 \%) \\
\pm 3 \%(90 \%-100 \%)\end{array}$ \\
\hline R.M. Young Wind Sentry cup anemometer & 1.34 & $\pm 0.5 \mathrm{~m} \mathrm{~s}^{-1}$ \\
\hline R.M. Young aerovanes & $3.75,7.25,14.75$, and 29.75 & $\pm 0.3 \mathrm{~m} \mathrm{~s}^{-1}$ \\
\hline Paroscientific Model 215 A pressure sensor & 2.3 & $\pm 0.05 \mathrm{mb}\left( \pm 0.2 \mathrm{mb} \mathrm{yr}^{-1}\right.$ long-term drift $)$ \\
\hline Campbell Scientific acoustic depth gauge & 3.2 & $\begin{array}{l} \pm 1 \mathrm{~cm}(0.4 \mathrm{in} .) \text { or } 0.4 \% \text { of distance } \\
\text { to target (whichever is greatest) }\end{array}$ \\
\hline $\begin{array}{l}\text { Kipp and Zonen CNR2-L net longwave } \\
\text { and shortwave radiation }\end{array}$ & 29.75 & $<10 \%$ (in daily totals) \\
\hline
\end{tabular}


values greater than $0^{\circ} \mathrm{C}$ were manually investigated for possible radiation error, since a temperature greater than $0^{\circ} \mathrm{C}$ is unlikely to occur within $30 \mathrm{~m}$ of an icecovered surface. Out of the 103982 total temperature observations, 721 observations were removed during the quality control process. To account for frozen wind instruments, a common issue with wind observations in Antarctica (Lazzara et al. 2012), the wind observations were removed if either the wind speed remained at zero for longer than a day or if the wind direction was constant for longer than a day. Using these criteria, it was determined that the cup anemometer located at $1.34 \mathrm{~m}$ was frozen for all of June 2011 and from April through September 2012.

In addition to the manual quality control process, the temperature data were investigated for instrumental biases. This is of concern because the vertical potential temperature gradient is analyzed to determine the stability of the surface layer and this vertical gradient is sensitive to biases that differ across the observational levels on the tower. As presented in Cassano et al. (2016), it was determined that the Tall Tower AWS 1.83and 3.75-m temperature observations exhibited a small bias with respect to the other temperature observations on the tower. Therefore, a $-0.09^{\circ} \mathrm{C}$ correction was applied to the $1.83-\mathrm{m}$ temperature observation and a $0.08^{\circ} \mathrm{C}$ correction was applied to the $3.75-\mathrm{m}$ temperature observation to account for these biases.

\section{Methods}

\section{a. Interpolation}

To better compare the AMPS forecasts to the Tall Tower observations, the AMPS data were vertically interpolated to the Tall Tower observation heights (Table 2). The AMPS temperatures were linearly interpolated to the observation heights using AMPS surface temperature and the temperature at the lowest two eta levels. The AMPS wind speed was interpolated to the observation heights assuming a logarithmic wind profile with a zero wind speed at the surface, and the wind speeds at the lowest two eta levels. For this calculation the AMPS roughness length of $0.001 \mathrm{~m}$ (Bromwich et al. 2013) was used and no stability correction was applied. The AMPS 2-m temperature and $10-\mathrm{m}$ winds were not used for the interpolation since these diagnostic variables are not directly tied to the physics of the model forecast. In the horizontal, the AMPS grid point located nearest to the location of the Tall Tower AWS, a distance of $2 \mathrm{~km}$, was used for comparison purposes. No horizontal interpolation was used given the relatively flat and uniform surface surrounding this site and is consistent with previous studies (Nigro et al. 2011, 2012).
This study analyzes profiles of potential temperature to determine the stability of the surface layer. Potential temperature anomaly profiles were used here because the change in potential temperature with height determines the stability of the atmosphere. When potential temperature increases with height, the atmosphere is statically stable, and when potential temperature decreases with height, the atmosphere is statically unstable. Potential temperature is not directly measured by the Tall Tower AWS and is not a direct output variable from AMPS; therefore, it was calculated for each dataset. For each of the datasets, the potential temperature was calculated at the Tall Tower temperature observation heights (Table 2). For this calculation, the Tall Tower $2.3-\mathrm{m}$ observed pressure was vertically interpolated to the temperature observation heights using the hypsometric equation. This interpolated pressure was used to calculate both the Tall Tower potential temperature and the AMPS potential temperature to remove a potential bias between the two datasets that is solely based on a pressure bias between the two datasets.

\section{b. Self-organizing maps}

The SOM method (Kohonen 2001) was used to analyze the range of potential temperature anomaly profiles observed by the Tall Tower AWS. The SOM is a neural network algorithm that uses an iterative learning process to identify a user-specified number of patterns within a dataset. This training seeks to minimize the squared difference between the training data and the resulting patterns. The SOM method pares down a large number of data records into a usable number of patterns by grouping similar data records together. This allows for an analysis of the dataset as a function of the patterns identified by the SOM (Nigro et al. 2011), providing additional information that is not available from an analysis of the data as a whole. For a thorough description of the SOM algorithm and training process, see Kohonen (2001) and Reusch et al. (2005). The SOM training method used for this study is presented in detail in Cassano et al. (2016) and is described briefly below.

For this study, the SOM was trained using the $100000+$ 10-min potential temperature anomaly profiles observed by the Tall Tower AWS. The potential temperature anomalies were used for this analysis because the stability of the atmosphere is dependent on the relative increase or decrease of potential temperature with height, not the magnitude of the potential temperature. The potential temperature anomaly profiles were calculated by subtracting the average potential temperature over the depth of the tower from each of the observed potential temperatures for each 10-min profile. The SOM was trained with the potential temperature anomaly profiles and a 

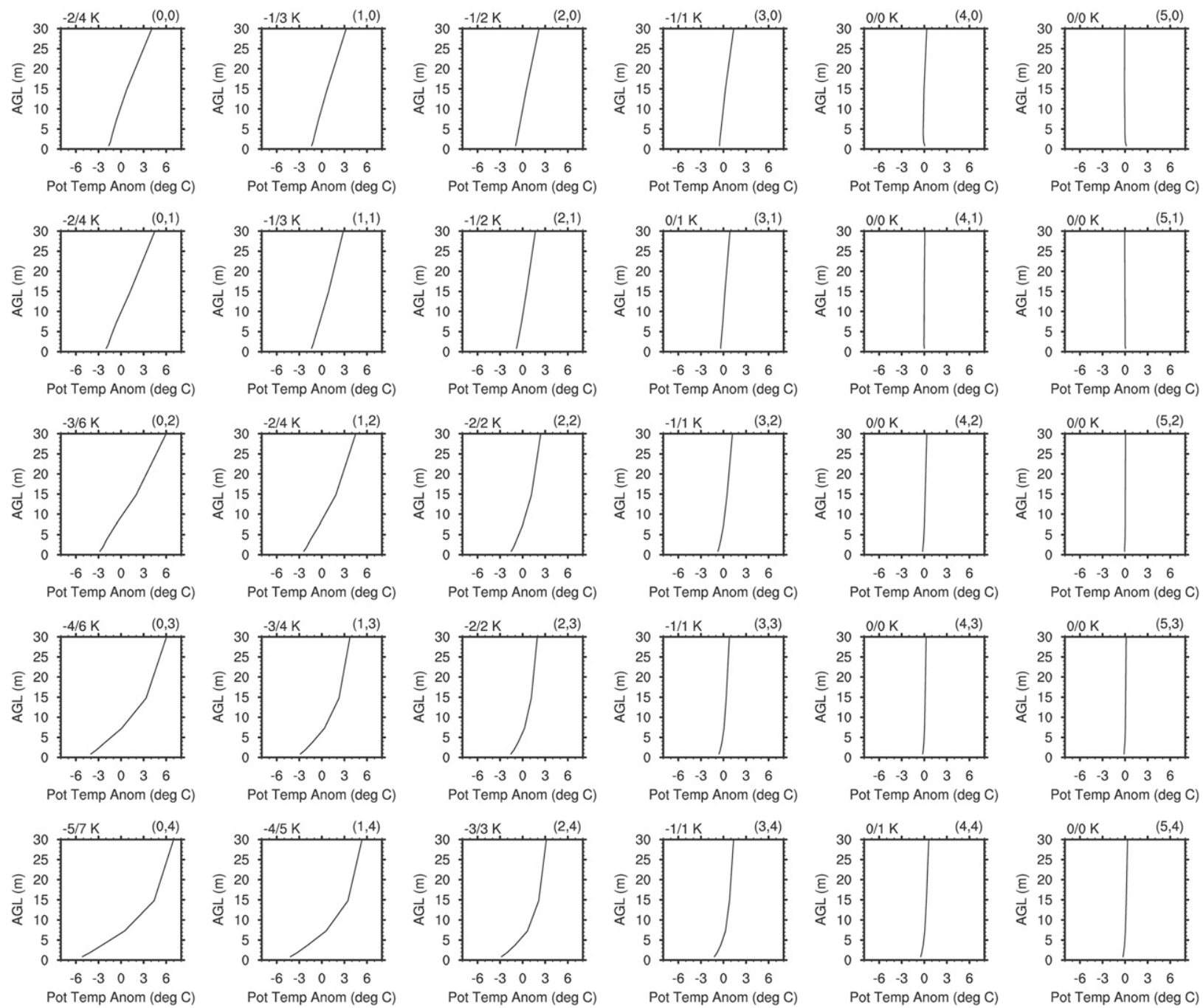

FIG. 2. Master SOM of the 30 Tall Tower potential temperature anomaly profiles. Numbers to the top left of each pattern indicate the minimum/maximum potential temperature anomalies over the depth of the profile. The numbers at the top right of each pattern indicate the column and row number of each pattern on the SOM.

range of SOM grid sizes from $8(4 \times 2)$ to $35(7 \times 5)$ patterns. The results from each of the grid sizes were analyzed to choose the optimal SOM grid size, which is not so large that patterns become so similar that discernable differences could not be determined and not so small that the results group nonsimilar patterns together causing patterns to be missing from the results. Using this information and the SOM expertise of the authors, it was determined that a $5 \times 6 \mathrm{SOM}$ grid, or 30 patterns, adequately captured the range of potential temperature anomaly patterns within the dataset, without producing patterns that were too similar (Cassano et al. 2016). This process is consistent with Reusch et al. (2005) and other SOM studies (Schuenemann and Cassano 2010; Higgins and Cassano 2010; Cassano et al. 2011; Seefeldt and Cassano 2012; DuVivier et al. 2016). The SOM derived from this training, referred to as the master SOM, is shown in Fig. 2.

Using the SOM, the AMPS forecasts were evaluated using the Tall Tower AWS observations. For this analysis, only the Tall Tower AWS observations that corresponded with the hourly AMPS output were used to provide a direct comparison between the two datasets. To conduct this analysis, each of the hourly Tall Tower AWS potential temperature anomaly profiles was matched to the master SOM pattern it most closely resembled, and this process is referred to as mapping the data to the SOM. The mapping process involved calculating the squared difference between the potential temperature anomaly profile of interest and the potential temperature anomaly profile for each of the master SOM patterns. The potential temperature anomaly 
profile of interest was mapped to the master SOM pattern that resulted in the minimum squared difference. This process was repeated for each of the Tall Tower AWS potential temperature anomaly profiles, resulting in a list of Tall Tower potential temperature anomaly profiles that map to each of the patterns on the master SOM. Using this information, the frequency at which each SOM pattern occurs within the Tall Tower dataset was calculated. Additionally, using this list of dates and times for each SOM pattern, pattern averages of other Tall Tower observations, such as wind speed, were calculated to identify the observed atmospheric behavior for each of the SOM patterns.

The AMPS data were evaluated with respect to the master SOM using two different methods. The first method used the mapping process described above to map each AMPS potential temperature anomaly profile to the master SOM pattern (Fig. 2) it most closely resembled. The result of this process was a list of the AMPS potential temperature anomaly profiles that map to each of the patterns on the master SOM. It should be noted that the list dates and times of the AMPS forecasts that map to a particular SOM pattern will not necessarily be the same as the list of dates and times of the Tall Tower observations that map to that SOM pattern. Using this information, the pattern frequencies within the AMPS dataset were calculated. The AMPS pattern frequencies were then compared to the Tall Tower pattern frequencies to determine how the frequencies of the SOM patterns differ between the AMPS forecasts and the Tall Tower observations.

The second method uses the list of dates and times that each of the Tall Tower potential temperature anomaly profiles map to each SOM pattern to create pattern averages of the corresponding AMPS forecasts. The pattern averages of Tall Tower observations and the corresponding AMPS forecasts were compared both graphically, by plotting both the AMPS and Tall Tower pattern averages together, and statistically to identify model errors as a function of the different SOM patterns.

\section{Results}

\section{a. Vertical potential temperature gradients}

To evaluate the stability of the surface layer, the vertical potential temperature difference over the depth of the tower in both the Tall Tower observations and the AMPS forecasts was calculated as the potential temperature at $29.75 \mathrm{~m}$ minus the potential temperature at $0.85 \mathrm{~m}$. Positive values represent a statically stable atmosphere and negative numbers represent a statically unstable atmosphere. Figure 3 shows histograms of the Tall Tower (Fig. 3a) and AMPS (Fig. 3b) vertical (a)

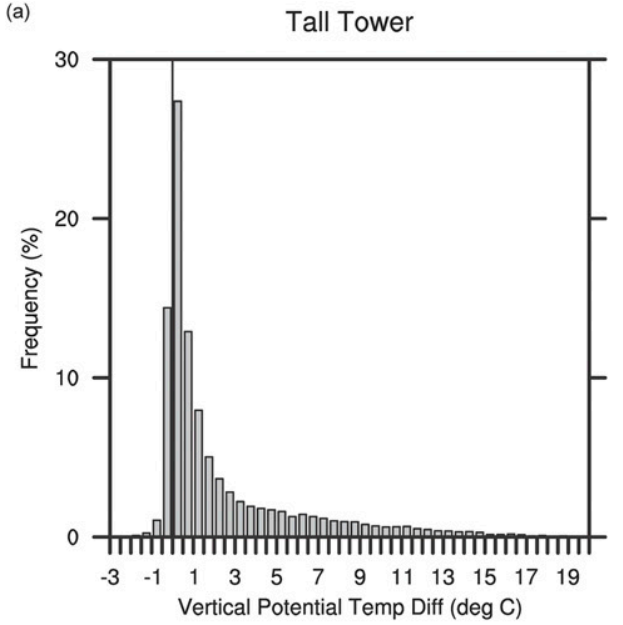

(b)

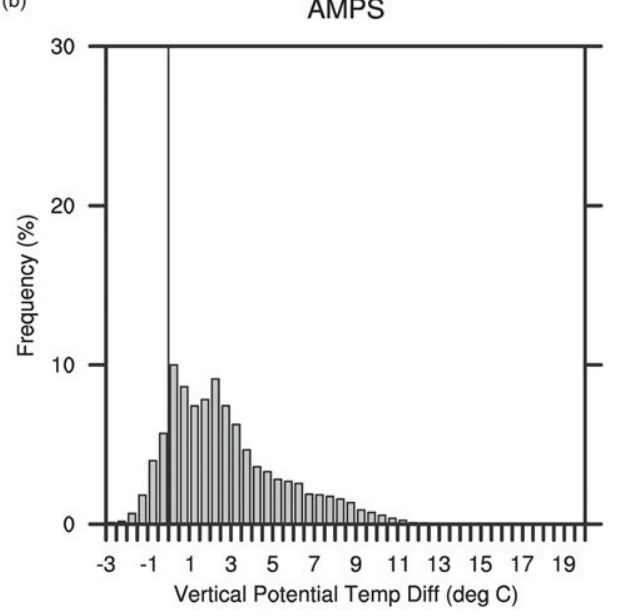

(c) Frequency Diff: AMPS - Tall Tower

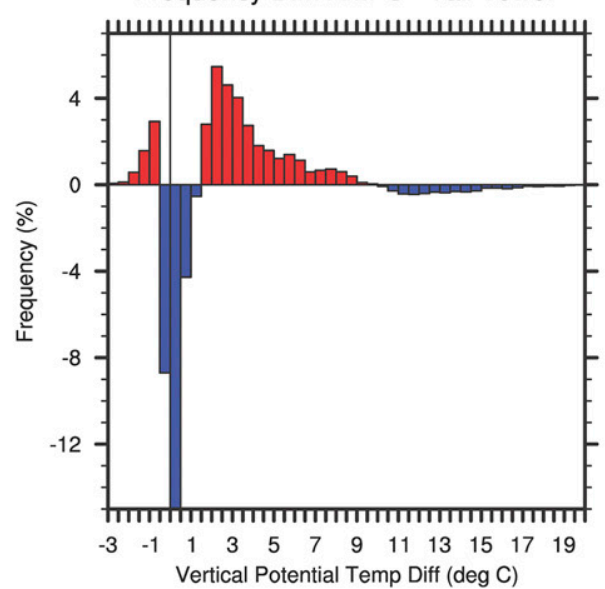

FIG. 3. Histograms of vertical potential temperature differences for (a) Tall Tower and (b) AMPS. (c) The frequency difference between (b) and (a) (AMPS - Tall Tower) with positive (negative) differences in red (blue). 




FIG. 4. Relationship between median (solid line) and 10th and 90th percentile (dashed lines) vertical potential temperature difference and average wind speed for the Tall Tower observations (black) and the AMPS 0-11-h (dark red), 12-23-h (red), and 24-35-h (orange) forecasts.

potential temperature differences, as well as the difference between the Tall Tower and AMPS (AMPS minus Tall Tower) histograms (Fig. 3c). Figure 3a indicates Tall Tower observes a high frequency of near-neutral profiles, with the vast majority of the vertical potential temperature differences ranging from $-0.5^{\circ}$ to $1.5^{\circ} \mathrm{C}$, as well as a long tail of very stable profiles with vertical potential temperature differences reaching as high as $17^{\circ} \mathrm{C}$. Figure $3 \mathrm{~b}$ indicates AMPS predicts a range of vertical potential temperature differences ranging from $-2.5^{\circ} \mathrm{C}$ (unstable profiles) to $11.5^{\circ} \mathrm{C}$ (stable profiles) with a less pronounced near-neutral peak than is seen in the observations. Figure $3 \mathrm{c}$ indicates AMPS underpredicts the frequency of the near-neutral profiles and overpredicts the frequency of the weakly unstable profiles with vertical potential temperature differences ranging from $-2.5^{\circ}$ to $-0.5^{\circ} \mathrm{C}$ and the moderately stable profiles with vertical potential temperature differences from $1.5^{\circ}$ to $9.5^{\circ} \mathrm{C}$. Figure $3 \mathrm{c}$ also shows AMPS fails to forecast the very stable profiles with vertical potential temperature differences greater than $11.5^{\circ} \mathrm{C}$ observed by the Tall Tower AWS.

Figure 4 shows the relationship between average wind speed over the depth of the tower and static stability in both the Tall Tower and AMPS datasets. This relationship is important because strong winds or strong vertical wind shear create mechanical mixing that can reduce the stability of the atmosphere. This is seen in the median and 90th percentile Tall Tower AWS observations, where the vertical potential temperature difference is largest for weak winds $\left(<4 \mathrm{~m} \mathrm{~s}^{-1}\right)$ and decreases with increasing wind speed. For weak winds, mechanical mixing is small and radiational cooling results in strong statically stable conditions. As wind speeds increase, mechanical mixing increases and the atmospheric stability is reduced, eventually mixing to neutral conditions in the median. For model forecasts, the amount of mechanical mixing generated by the winds is dependent on the PBL and surface-layer parameterization used in the model. Therefore, Fig. 4 highlights the impact of mixing on the static stability forecast in the model compared to the observations. In Fig. 4, AMPS is evaluated over various forecast times: $0-11 \mathrm{~h}$ (dark red), $12-23 \mathrm{~h}$ (red), and $24-35 \mathrm{~h}$ (orange). The results indicate the relationship between wind speed and vertical potential temperature difference is fairly consistent across all forecast hours. This is due to the fact that the relationship between wind speed and static stability is controlled by the model physics and thus does not vary much with forecast duration. Figure 4 shows the AMPS forecasts are more statically stable than the Tall Tower observations in the median (solid lines). At low wind speeds (less than $3 \mathrm{~m} \mathrm{~s}^{-1}$ ) the AMPS vertical potential temperature difference is approximately $1^{\circ} \mathrm{C}$ greater than the Tall Tower vertical potential temperature difference. This error increases to approximately $2^{\circ} \mathrm{C}$ at wind speeds of approximately $4 \mathrm{~m} \mathrm{~s}^{-1}$ and then decreases back to $1^{\circ} \mathrm{C}$ with increasing wind speeds. This is also reflected at very strong wind speeds where AMPS fails to mix toward neutral conditions in the median. These results suggest AMPS does not generate enough mechanical mixing in the median across all wind speeds, which is consistent with the findings of Steinhoff et al. (2009) and Wille et al. (2016). There is also the possibility that AMPS has a negative radiation bias, which could also lead to the results shown in Fig. 4. This will be discussed in further detail later in the paper, based on additional information provided by the SOM analysis.

It is also noteworthy that for wind speeds $<3 \mathrm{~m} \mathrm{~s}^{-1}$, the 10th percentile AMPS vertical potential temperature difference (dashed lines) is about $0.5^{\circ} \mathrm{C}$ less than the near-neutral profiles observed by Tall Tower, and the 90th percentile AMPS vertical potential temperature difference (dashed lines) is approximately $1^{\circ}-3^{\circ} \mathrm{C}$ less than the strongly stable profiles observed by Tall Tower. This is consistent with Fig. 3, where AMPS is shown to overpredict the frequency of the unstable profiles and underpredict the frequency of the strong statically stable profiles, which suggests that in light wind conditions AMPS generates more unstable conditions when the surface is being radiatively heated and generates overly weak stable conditions when the surface is being radiatively cooled. 
This suggests a possible change in the model bias from too little mechanical mixing under conditions of light winds and surface heating (10th percentile vertical potential temperature difference) to too much mechanical mixing under conditions of light winds and strong radiative cooling (90th percentile vertical potential temperature difference).

\section{b. Self-organizing maps analysis}

The SOM method is used to identify the range of potential temperature anomaly profiles observed at Tall Tower. The master SOM (Fig. 2) indicates the potential temperature profiles observed at Tall Tower range from weakly unstable in the top-right corner to strong static stability in the bottom-left corner. The weakly unstable pattern $(5,0)$ has a median vertical potential temperature difference of $-0.3^{\circ} \mathrm{C}$ (not shown). The remaining patterns range from near neutral to varying magnitudes of statically stable. The stability of these patterns increases when moving from the right to the left side of the SOM. The patterns with the strongest static stability are located in the bottom-left corner. Pattern $(0,4)$ represents the most statically stable pattern observed by Tall Tower with vertical potential temperature differences of $13.5^{\circ} \mathrm{C}$ in the median and $16.8^{\circ} \mathrm{C}$ at the 90th percentile (not shown).

The frequency of each SOM pattern within the Tall Tower (Fig. 5a) and AMPS (Fig. 5b) datasets is shown. The Tall Tower AWS observes the weakly unstable and near-neutral patterns in columns 4 and 5 approximately $59 \%$ of the time, with the unstable pattern $(5,0)$ occurring approximately $6 \%$ of the time. The near-neutral patterns $(5,1)$ and $(5,2)$ occur with the highest frequency in the Tall Tower dataset. Conversely, AMPS predicts the weakly unstable and near-neutral patterns in columns 4 and 5 approximately $32 \%$ of the time, with the unstable pattern $(5,0)$ occurring approximately $10 \%$ of the time. The Tall Tower AWS observes the stable patterns in columns $0-3$ approximately $41 \%$ of the time (Fig. 5a), while AMPS predicts these stable patterns occur approximately $58 \%$ of the time, with pattern $(3,4)$ occurring with the highest frequency and the most stable pattern $(0,4)$ occurring with the lowest frequency (Fig. 5b).

Figure $5 \mathrm{c}$ shows the difference between the AMPS and Tall Tower frequencies with dark red and dark blue shading indicating statistically significant differences between the two datasets. All of the frequency differences, with the exception of one pattern, are statistically significant. The frequency differences illustrated in Fig. $5 \mathrm{c}$ are given as the difference (top number in each box) and the percent difference with respect to the Tall Tower frequency (shown in parentheses). The red shading in pattern $(5,0)$ indicates AMPS overpredicts the (a)

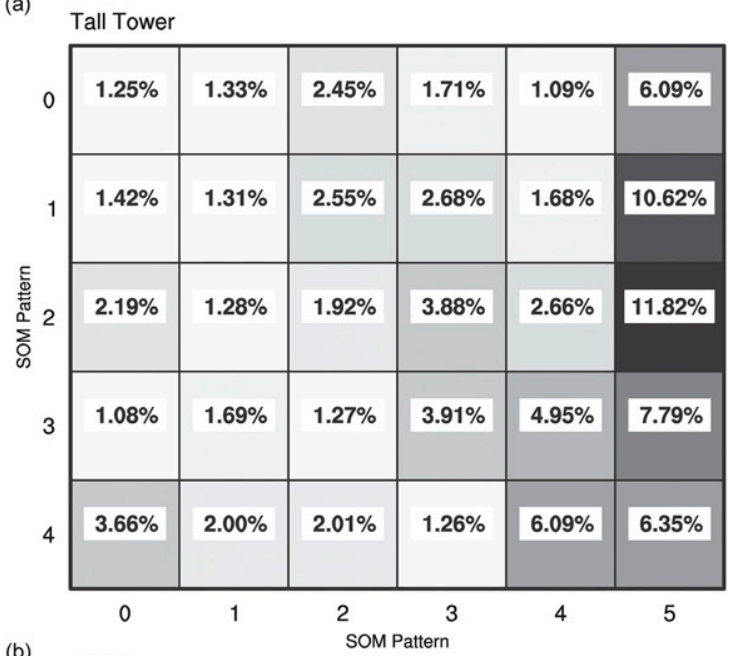

(b)

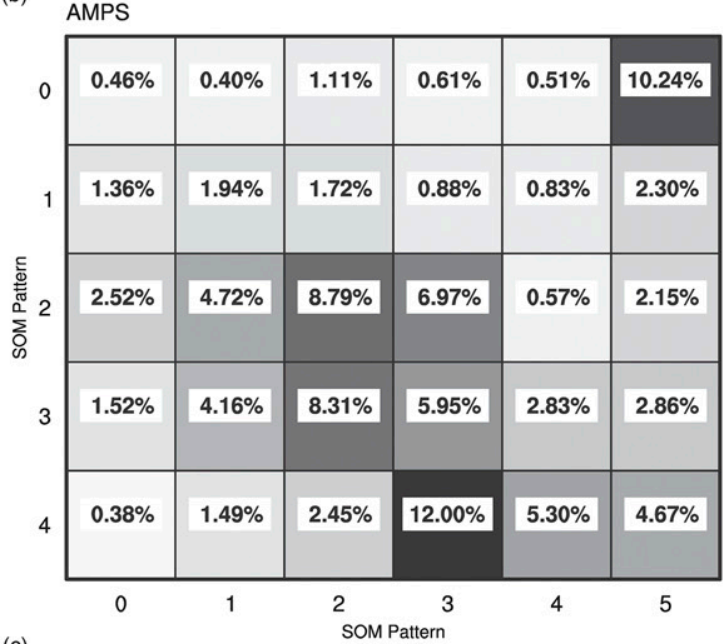

(c) Frequency Diff: AMPS - Tall Tower

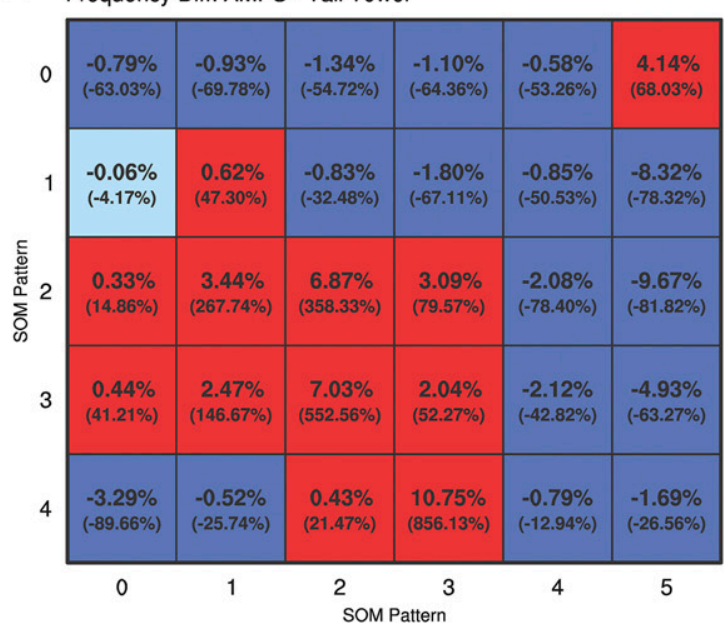

FIG. 5. Frequency of occurrence for each of the 30 SOM patterns for (a) Tall Tower and (b) AMPS. (c) The frequency difference between (b) and (a) (AMPS - Tall Tower) with positive (negative) differences in red (blue). Dark red and dark blue shadings indicate a statistically significant difference. The percent frequency difference with respect to the Tall Tower frequencies is shown in parentheses. 
frequency of this weakly unstable profile, which is consistent with AMPS forecasting stronger statically unstable conditions than the Tall Tower observations (Figs. 3 and 4). The blue shading in the remainder of columns 4 and 5 in Fig. 5 c indicates AMPS underpredicts the frequency of the near-neutral to weakly stable patterns observed by Tall Tower and is also consistent with the results shown in Figs. 3 and 4. As noted in the previous paragraph AMPS overpredicts the frequency of the stable patterns in columns $0-3$ by $17 \%$, but this overprediction is not uniformly distributed across these columns (Fig. 5c). AMPS overpredicts the moderately stable patterns from the bottom-center to the left-center portion of the SOM and underpredicts the remaining stable patterns. These SOM-based results are consistent with the conclusions drawn from Fig. 3, which showed AMPS overpredicts moderately stable conditions and underpredicts strongly stable conditions. Pattern $(0,4)$ represents the most statically stable profile observed by Tall Tower. AMPS forecasts this pattern $0.38 \%$ of the time, while Tall Tower observes this pattern $3.66 \%$ of the time. This equates to an approximately $90 \%$ underrepresentation of this pattern in the AMPS dataset.

The AMPS evaluation described above was based on separate mapping of the AMPS and Tall Tower data to the SOM and thus allowed us to compare the frequency with which AMPS simulates each of the SOM potential temperature profiles to the frequency with which each of these patterns was observed. The remainder of our analysis will focus on a comparison of AMPS and Tall Tower data at matching times and will use the list of dates and times generated by mapping the Tall Tower data to the master SOM, as described in section 3. This analysis allows us to better understand how AMPS differs from the Tall Tower observations when a given potential temperature pattern is observed by the AWS.

In Fig. 6, the average Tall Tower potential temperature anomaly profiles are shown by the black lines and the corresponding AMPS forecasts of potential temperature anomalies are shown by the red lines, indicating the difference between the observed atmospheric stability (black lines) and the modeled atmospheric stability (red lines) for each SOM pattern. For the near-neutral patterns in columns 4 and 5, with the exception of the topright pattern $(5,0)$, AMPS consistently predicts a more stable profile than the Tall Tower observations (Fig. 6), which contradicts most of the literature on modeling static stability (Derbyshire 1999; Poulos and Burns 2003; Tjernstrom et al. 2004; Holtslag 2006; Rinke et al. 2012; Holtslag et al. 2013; Wille et al. 2016). For the stable patterns in columns 0-3, AMPS predicts more stable profiles than the Tall Tower observations for the weakly stable patterns in column 3 and transitions to predicting less stable profiles than Tall Tower for the strongly stable patterns in column 0 . The magnitude at which AMPS over- or underpredicts the stability of each pattern is shown in Fig. 7, where the difference between the AMPS vertical potential temperature difference and the Tall Tower vertical potential temperature difference is shown for each pattern. For the weakly unstable pattern $(5,0)$ AMPS underpredicts the stability of the pattern by $0.1^{\circ} \mathrm{C}$ in the median and $0.6^{\circ} \mathrm{C}$ at the 10th percentile (Fig. 7), indicating, in general, AMPS predicts more unstable conditions than the Tall Tower observations for this pattern. Conversely, in the 90th percentile, AMPS overpredicts the stability of this pattern by $2.5^{\circ} \mathrm{C}$ (Fig. 7), indicating there are times when AMPS predicts more stable conditions than the Tall Tower observations for this pattern. For the near-neutral patterns in columns 4 and 5, with the exception of pattern $(5,0)$, the magnitude of the AMPS overprediction of the stability ranges from $0.1^{\circ}$ to $1.3^{\circ} \mathrm{C}$ in the median and reaches up to $5.3^{\circ} \mathrm{C}$ at the 90 th percentile (Fig. 7). For the weakly stable patterns in column 3, AMPS overpredicts the stability from $0.9^{\circ}$ to $1.5^{\circ} \mathrm{C}$ in the median and up to $5.0^{\circ} \mathrm{C}$ in the 90 th percentile. AMPS underpredicts the stability in the more stable patterns in columns $0-2$, with the underprediction reaching $5.5^{\circ} \mathrm{C}$ in the median and $7.1^{\circ} \mathrm{C}$ in the 10 th percentile for the strongly stable pattern $(0,4)$. In general AMPS overpredicts the stability for near-neutral to weakly stable conditions (right side of the SOM) and underpredicts the stability for more stable conditions (left side of the SOM).

Figure 8 shows the difference between the AMPS and Tall Tower wind speeds at the lowest-level wind speed observation height $(3.75 \mathrm{~m})$. This near-surface wind speed will, in part, control the strength of the mechanical mixing present in both the observations and model forecasts. For the unstable and near-neutral patterns in columns 4 and 5 , with the exception of patterns $(4,0)$ and $(4,2)$, AMPS has a negative wind speed bias. For the weakly unstable pattern $(5,0)$, the negative wind speed bias results in too little mechanical mixing, which under surface heating conditions creates unstable conditions and is consistent with the negative stability bias seen in Fig. 7. For the near-neutral patterns in the remainder of columns 4 and 5 , the negative wind speed bias results in too little mechanical mixing, which under surface cooling conditions creates stable conditions and is consistent with the positive stability bias seen in Fig. 7 . For the stable patterns in columns 0-3, AMPS has a consistent positive wind speed bias. The wind speed bias is largest for the strongly stable patterns in the bottom-left corner, with a maximum median wind speed bias of $3.2 \mathrm{~m} \mathrm{~s}^{-1}$ for pattern $(0,4)$. The positive wind speed bias for these patterns results in too much mechanical mixing, which 

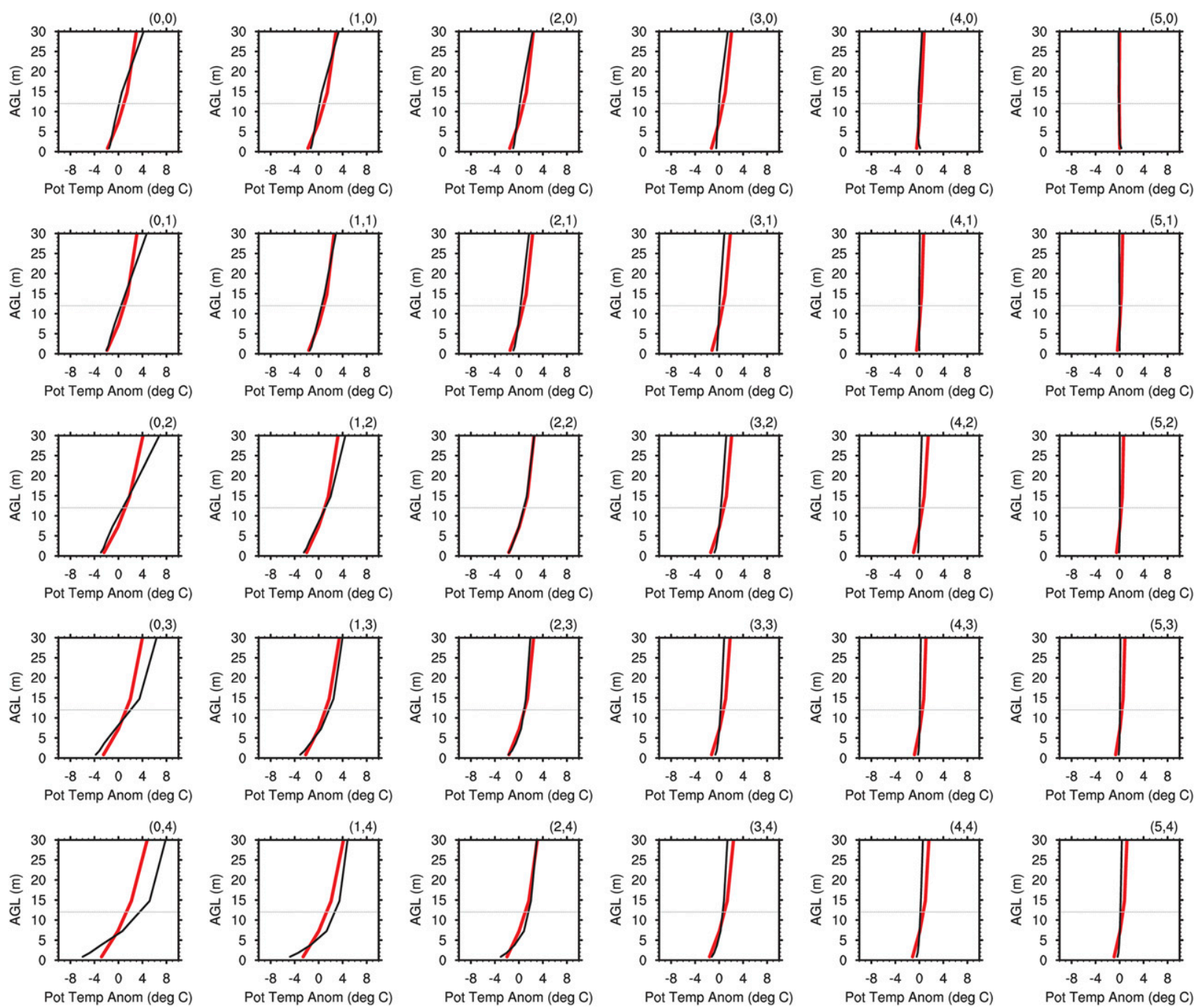

FIG. 6. The 30 SOM patterns average potential temperature anomaly profiles of Tall Tower observations (black line) and AMPS forecasts (red line).

under surface cooling conditions creates less stable conditions. This is consistent with the negative stability biases for the strongly stable patterns on the left side of the SOM (Fig. 7), but is inconsistent with the positive stability biases for the weakly stable patterns in column 3 . This implies something other than mechanical mixing is causing the stability errors in AMPS for the patterns in column 3 , and these other processes may also be acting to modulate the stability biases seen across the entire SOM.

Comparison of the Tall Tower (black line) and AMPS (red line) wind speed profiles (Fig. 9) and potential temperature profiles (Fig. 10) provides additional insights into the source of the AMPS stability errors. Note that Fig. 10 shows the potential temperature profiles, in contrast to the potential temperature anomaly profiles shown in Fig. 6. Unlike the potential temperature anomaly profiles, the potential temperature profiles indicate potential temperature biases between the observations and forecasts, allowing us to assess the presence of cold or warm biases in the AMPS forecasts and thus providing additional information about possible errors associated with the modeled energy budget.

For the near-neutral patterns in the bottom-right corner, AMPS generally has a negative wind speed bias over the depth of the tower with the magnitude of the bias increasing with height (Fig. 9). The AMPS potential temperature profiles for these patterns closely resemble the Tall Tower observations at the top of the tower, with a cold bias near the surface (Fig. 10). In order for AMPS to accurately forecast the potential temperatures at the top of the tower and have a surface cold bias, it is likely AMPS is accurately capturing the large-scale forcing related to the temperature of these patterns, but has a negative radiation bias at the surface. 


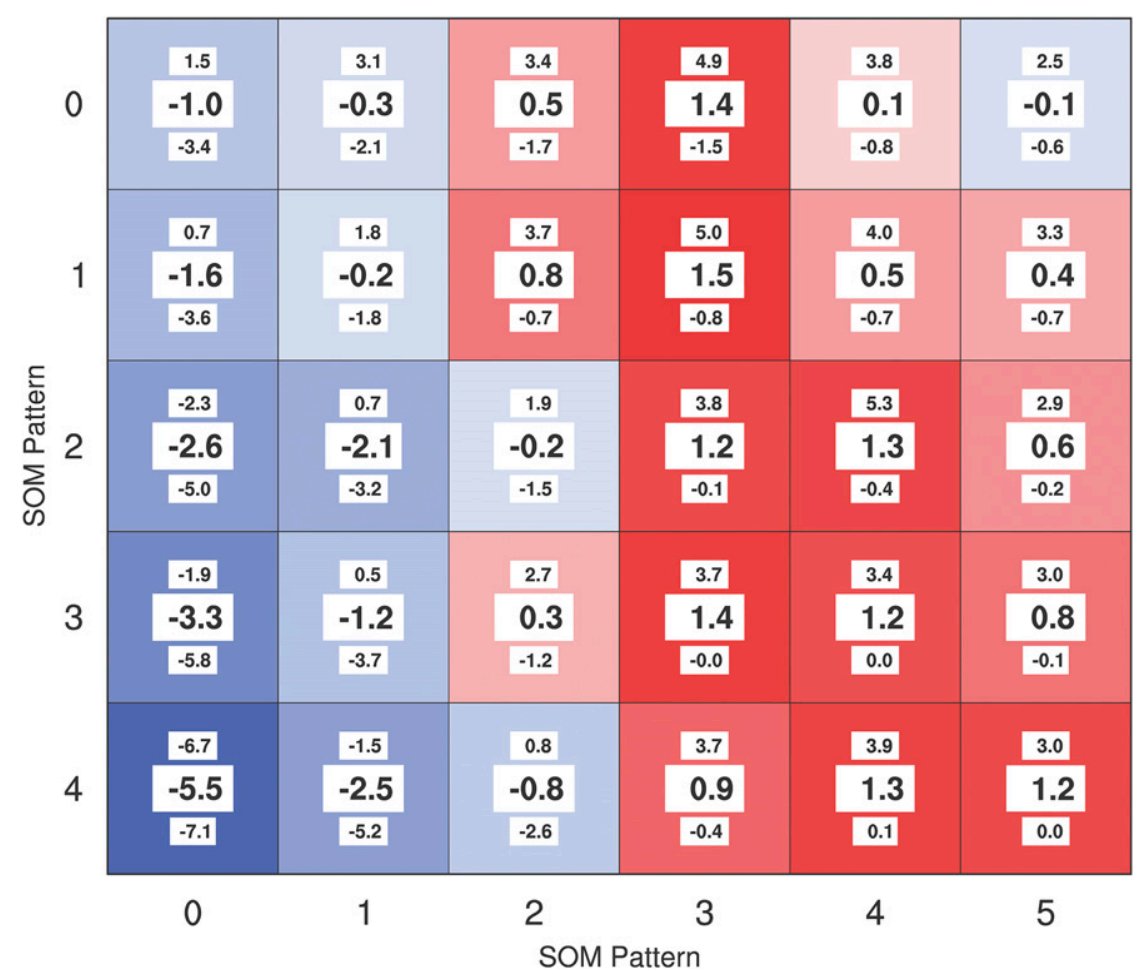

FIG. 7. Median difference between AMPS and Tall Tower vertical potential temperature difference for each of the 30 SOM patterns. Red colors indicate a positive AMPS bias in the median, and blue colors indicate a negative AMPS bias. Darker shading indicates larger median values. The 10th and 90th percentiles are shown below and above the median values, respectively.

The negative radiation bias paired with the weaker mechanical mixing due to the negative wind speed bias and weaker wind shear over the depth of the tower is likely driving the positive stability biases for these patterns (Fig. 7).

For the stable patterns in columns $0-3$, a range of model errors exists across these patterns. In the bottomleft corner, there is a positive wind speed bias over the depth of the tower (Fig. 9), indicating the large-scale pressure gradient force for these patterns is likely too large in AMPS. Additionally, for these patterns, the AMPS mean potential temperature averaged over the depth of the tower is similar to the mean potential temperature observed by Tall Tower, but has a warm bias at the surface and a cold bias at the top of the tower. Therefore, for these patterns, the positive wind speed bias is likely generating too much mechanical mixing, causing warmer potential temperature near the surface and colder potential temperatures aloft, and an underrepresentation of the static stability in AMPS (Fig. 7).

For the moderately stable patterns in the top-left corner, there is a positive wind speed bias near the surface that decreases to near zero at the top of the tower (Fig. 9) and a surface warm bias that decreases to near zero at the top of the tower (Fig. 10). The positive wind speed bias near the surface likely generates too much mechanical mixing, causing the warm bias and the negative stability bias (Fig. 7) in these patterns. In contrast to the strongly stable patterns in the bottom-left corner, where the warm bias is confined to near the surface, the warm bias extends over the depth of the tower in these patterns. It is possible a cold bias exists above the top of the tower in these patterns, which would be consistent with too much mechanical mixing in AMPS, but it is not possible to verify this without additional observations.

In column 3, the AMPS potential temperature forecasts resemble the Tall Tower observations at the top of the tower and have a cold bias near the surface (Fig. 10). Similar to the near-neutral patterns in the bottom-right corner, it is likely AMPS accurately captures the largescale forcing for these patterns and has a negative radiation bias at the surface. The large-scale forcing for these patterns can be inferred from Fig. 12 in Cassano et al. (2016), which depicts the AMPS forecast sea level pressure for each of the SOM patterns. The patterns in column 3 have a synoptic cyclone located off the coast of West Antarctica and a pressure gradient that would drive southerly winds at the location of Tall Tower. 


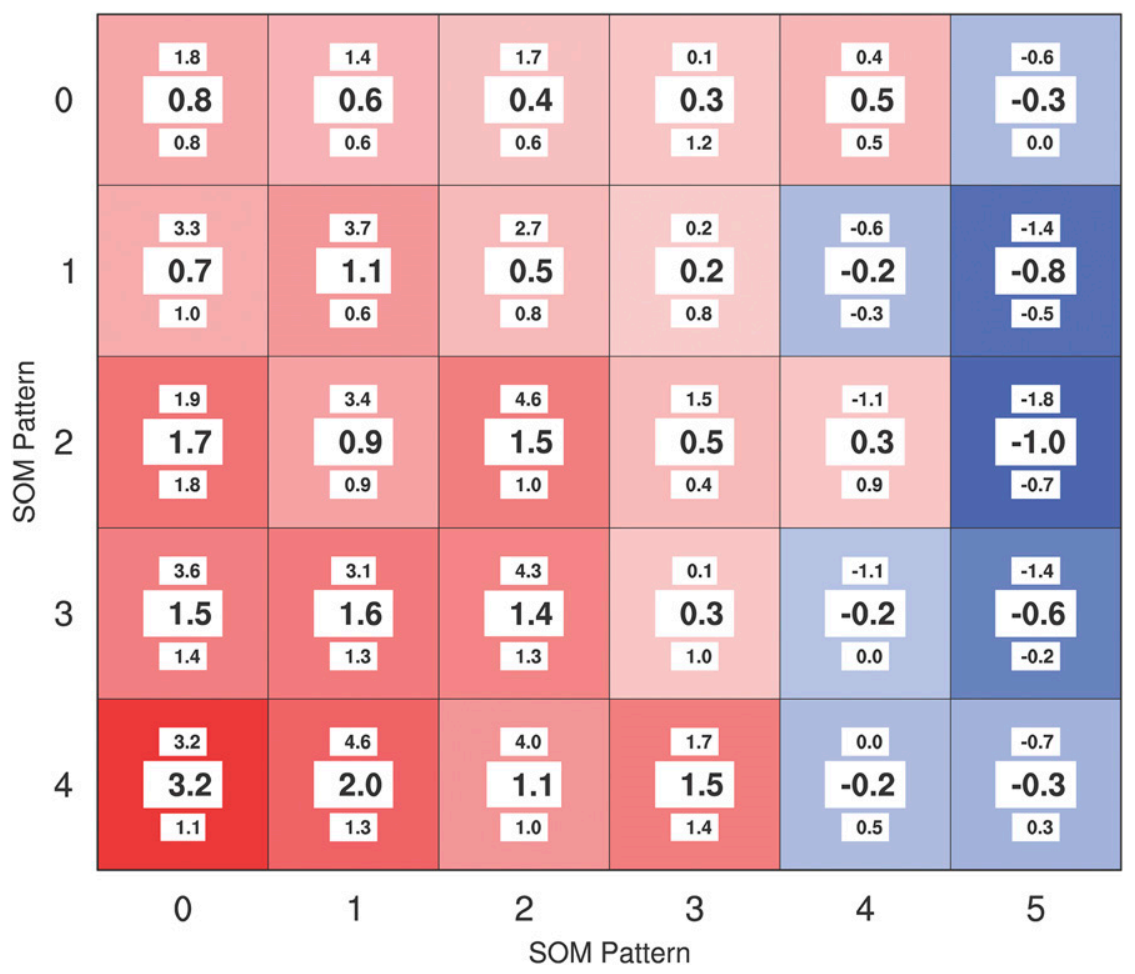

FIG. 8. As in Fig. 7, but for the lowest-level wind speed.

Unlike the patterns in the bottom-right corner, the patterns in column 3 have a positive wind speed bias near the surface (Fig. 9). This indicates that for these patterns the negative radiation bias must dominate the additional mixing driven by the faster wind speeds to result in the positive stability bias for these patterns (Fig. 7). For the patterns in column 2, which represent a transition between the patterns on the left side of the SOM and the patterns in column 3, it is likely these patterns have a combination of model errors related to the positive wind speed bias shown in the patterns on the left side of the SOM and the negative radiation bias in the column 3 patterns.

From this analysis, it is difficult to identify the source of the negative radiation error in the near-neutral patterns in the bottom-right corner and the stable patterns in column 3. It is possible that the negative radiation bias is related to an underrepresentation of the cloud cover in AMPS, as identified by Bromwich et al. (2013) and Valkonen et al. (2014), or to a dry bias in AMPS, as identified by Wille et al. (2016) using the Tall Tower observations and AMPS output. An underrepresentation of the cloud cover or a dry bias would result in less longwave radiation down and a negative radiation bias in AMPS, especially in winter when no shortwave radiation is available to offset the negative longwave bias. Additionally, the relationship between the vertical potential temperature difference and the wind speeds in Fig. 4 supports the possibility of a negative radiation bias across a range of wind speeds. Therefore, it is likely that the negative radiation bias is present, at least to some degree, in the other patterns across the SOM but is offset, and thus is not as evident in the SOM analysis, by other model errors such as additional mixing due to stronger modeled winds.

\section{c. Model statistics by forecast hour}

The model statistics are further investigated by examining the modeled behavior as a function of stability (as shown by the four corner SOM patterns) and forecast hour (0-11 h, dark red; $12-23 \mathrm{~h}$, red; 24-35 h, orange). The pattern averages of the bias, root-mean-square error (RMSE), and the correlation are shown for the wind speed profiles (Fig. 11) and the potential temperature profiles (Fig. 12). Since the corner patterns in the SOM represent the extreme range of conditions present in the training data, the analysis below uses these patterns to illustrate model errors for weakly unstable $(5,0)$, nearneutral $(5,4)$, moderately stable $(0,0)$, and strongly stable $(0,4)$ conditions.

The increase in bias and RMSE and decrease in correlation for both potential temperature and wind speed moving from the top to the bottom of Figures 11 and 12 indicate model errors tend to increase with increasing 

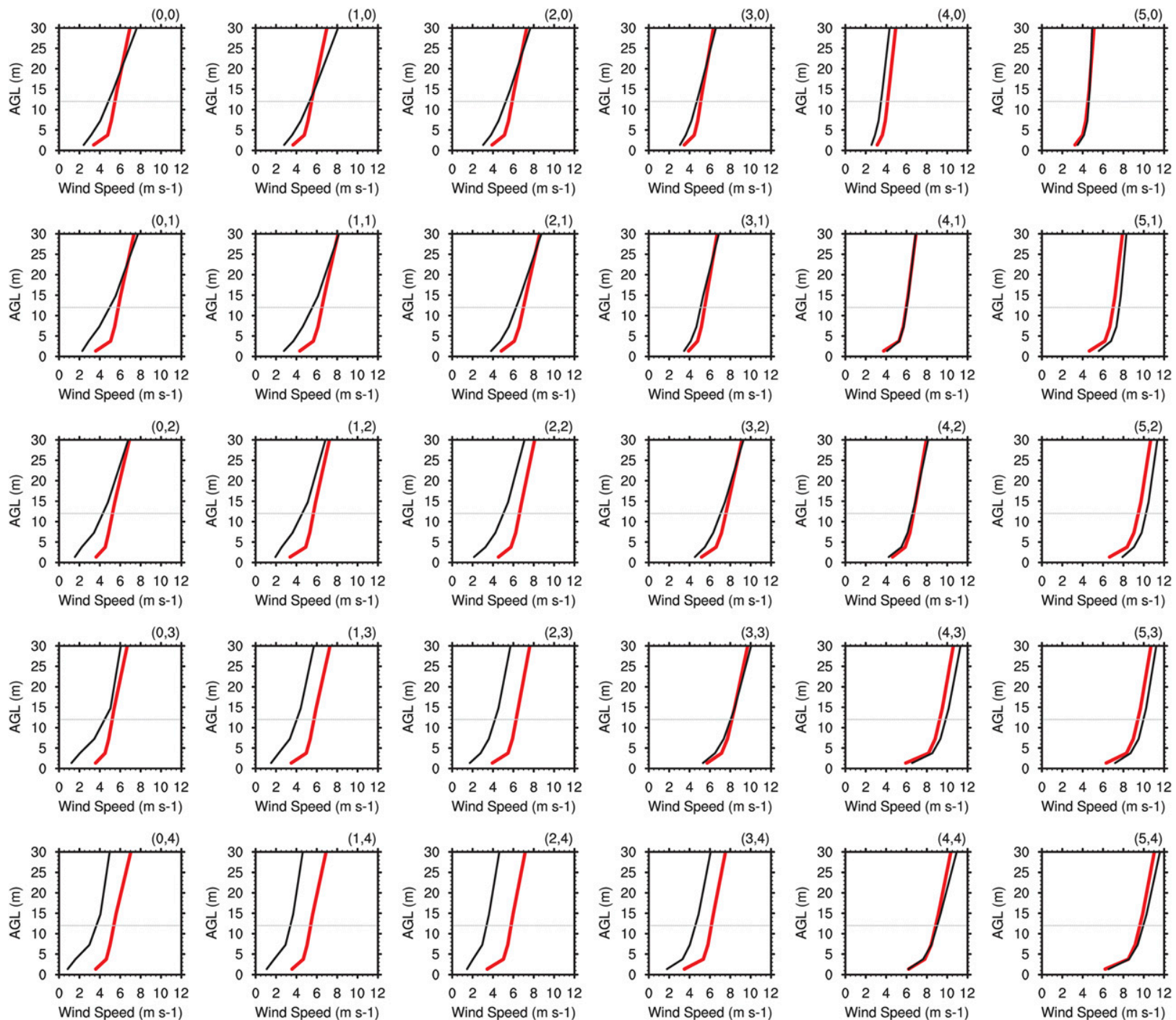

FIG. 9. The 30 SOM patterns average wind speed profiles of Tall Tower observations (black line) and AMPS forecasts (red line).

static stability. The wind speed RMSE (Fig. 11) shows errors on the order of $2 \mathrm{~m} \mathrm{~s}^{-1}$ for the weakly unstable pattern $(5,0)$. These errors increase to $2-3 \mathrm{~m} \mathrm{~s}^{-1}$ for the near-neutral $(5,4)$ and the stable $(0,0)$ patterns and reach $3-4 \mathrm{~m} \mathrm{~s}^{-1}$ for the strong stable pattern $(0,4)$. The potential temperature RMSE is on the order of approximately $3^{\circ} \mathrm{C}$ for the weakly unstable pattern and increases to $4^{\circ}-6^{\circ} \mathrm{C}$ for the strongly stable pattern (Fig. 12). The correlations show a similar trend with the wind speed correlation being approximately 0.7 for the weakly unstable pattern $(5,0)$ and decreasing to roughly zero for the strongly stable pattern $(0,4)$. Likewise, the potential temperature correlation is close to one for the weakly unstable pattern $(5,0)$ and decreases with increasing stability to approximately 0.8 for the strong static stability pattern $(0,4)$. Given the difficulty in simulating stable boundary layers, these results are not surprising.

For the near-neutral pattern $(5,4)$, the forecast skill for wind speed improves with forecast hour (Fig. 12). The bias ranges from approximately -0.5 to $-1.5 \mathrm{~m} \mathrm{~s}^{-1}$ over the depth of the tower for the $0-11-\mathrm{h}$ forecasts (dark red) and decreases to 0 to $-0.5 \mathrm{~m} \mathrm{~s}^{-1}$ over the depth of the tower for both the 12-23-h (red) and 2435 - $\mathrm{h}$ (orange) forecasts. The RMSE (correlation) is largest (smallest) for the 0-11-h forecasts (dark red) and smallest (largest) for the 12-23-h forecasts (orange). This suggests a potential problem with the wind speed initialization for this near-neutral pattern. Interestingly, the spread in the wind speed bias and RMSE over forecast hour is not reflected in the potential temperature bias and RMSE. If the surface cold bias in this pattern were driven by the negative 

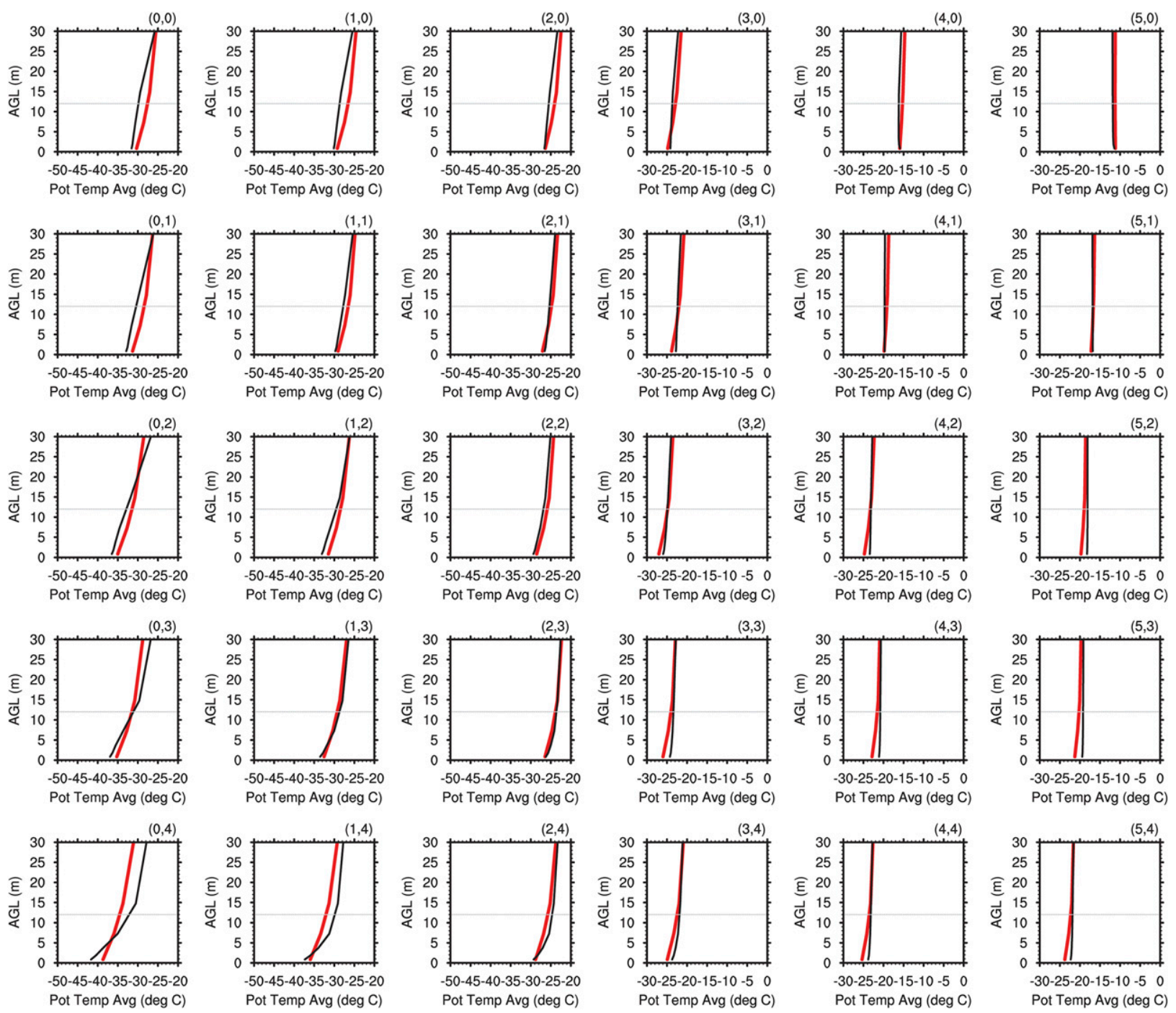

FIG. 10. As in Fig. 9, but for potential temperature.

wind speed bias near the surface, it would be expected that the change in wind speed bias with forecast hour would also be reflected in a change in potential temperature bias with forecast hour. This supports a negative radiation bias in this pattern.

In contrast to the decreasing model wind speed error with forecast time seen in the near-neutral pattern $(5,4)$, the weakly unstable pattern $(5,0)$ shows very little change in model wind speed error statistics as a function of forecast time and the moderately stable pattern $(0,0)$ and the strongly stable pattern $(0,4)$ generally show an increase in model wind speed errors with increasing forecast duration (Fig. 11). For the moderately $(0,0)$ and strongly stable $(0,4)$ patterns the potential temperature errors also increase with forecast duration (Fig. 12), which is consistent with the positive wind speed bias resulting in strong mechanical mixing and the surface warm bias for these patterns.

The 0-, 12-, and 24-h forecasts were analyzed using the same method as in Figs. 11 and 12 to analyze the performance of the initial conditions. The results are included as Figs. S1 and S2 in the online supplemental material. These figures indicate that the AMPS initial conditions have larger errors (larger RMSE and lower correlation) than the 12- and 24-h forecasts for SOM pattern $(0,0)$ for wind speed and temperature and SOM pattern $(5,4)$ for wind speed, similar errors for SOM pattern $(5,0)$ for wind speed and temperature and node $(5,4)$ for temperature, and smaller errors for node $(0,4)$ for both temperature and wind speed. As noted above, the SOM analysis presented here is useful in identifying 
Avg
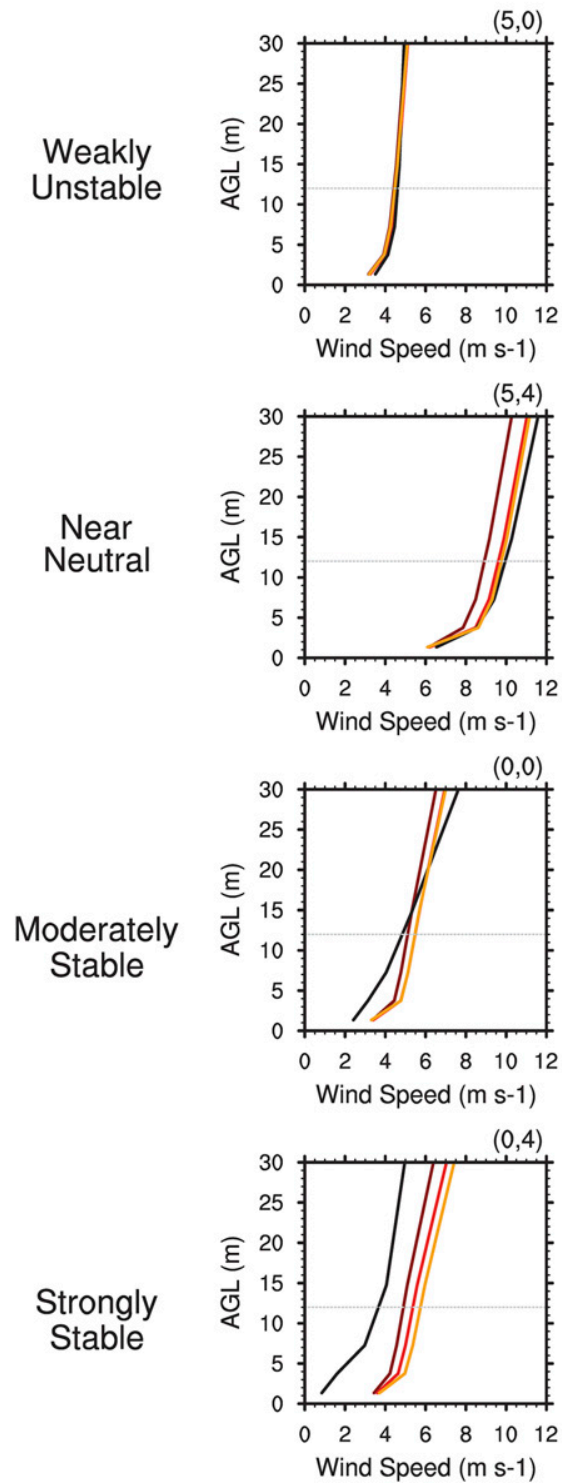

Bias
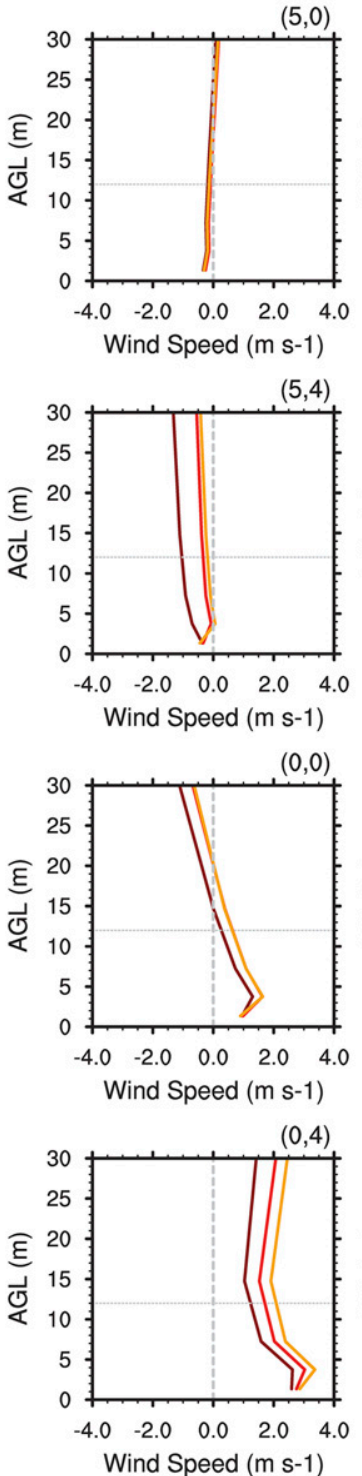

RMSE

Corr
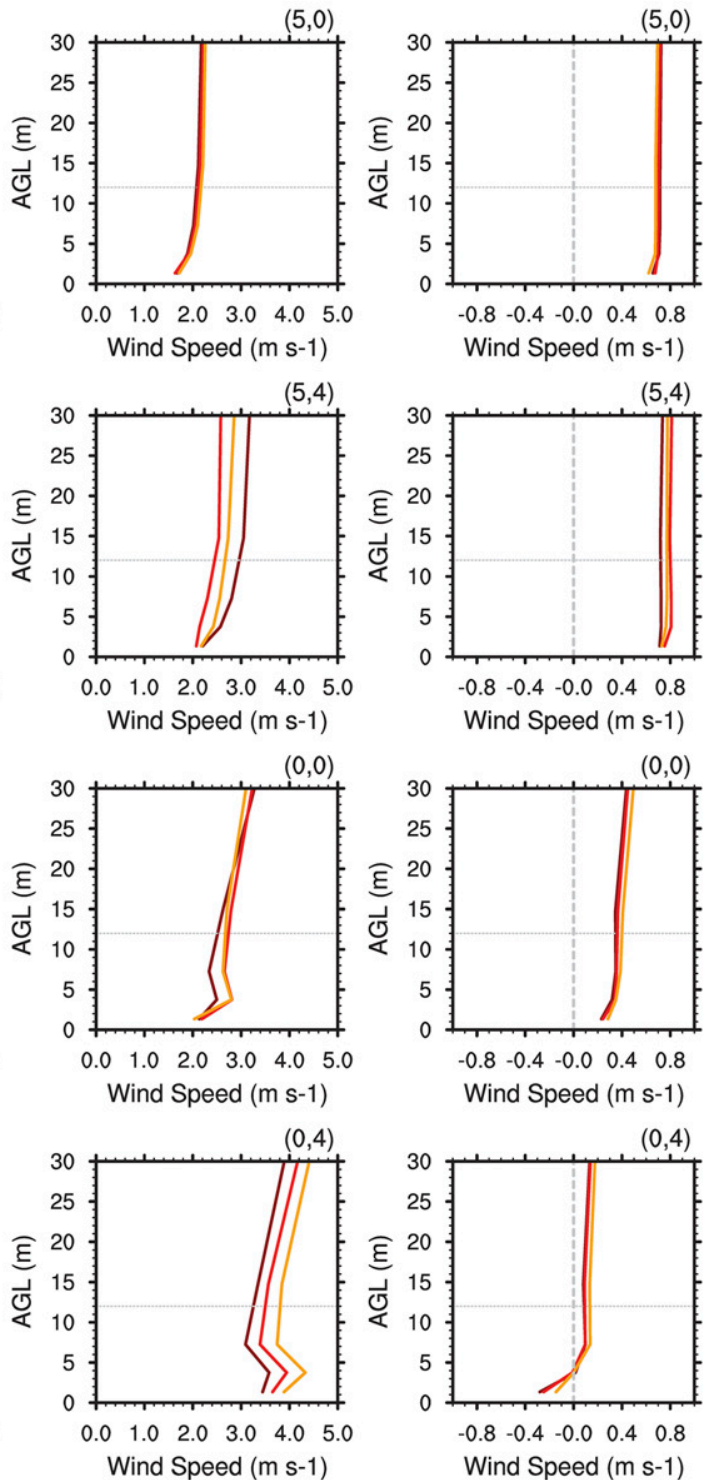

FIG. 11. SOM patterns (first column) average wind speed, (second column) bias, (third column) RSME, and (fourth column) correlation for the (top row) weakly unstable, (second row) near-neutral, (third row) moderately stable, and (bottom row) strongly stable four corner patterns of the SOM. The lines show the Tall Tower observations (black line) and the 0-11-h (dark red line), 12-23-h (red line), and 24-35-h (orange line) AMPS forecasts.

stability-dependent errors, in this case in the model initial conditions.

\section{Discussion and conclusions}

This paper uses observations from the Tall Tower AWS to evaluate forecasts of the surface layer in AMPS. Comparison of the AMPS forecasts to the Tall Tower observations indicates AMPS underpredicts the frequency of the near-neutral profiles observed by Tall
Tower and instead overpredicts the frequency of the unstable profiles and weak to moderately stable profiles observed by Tall Tower. It is also shown that AMPS does not forecast the strongest stability profiles observed by Tall Tower (Figs. 3 and 5). The relationship between the wind speed and the vertical potential temperature difference is evaluated to understand the impact of mixing on the static stability for each dataset. The AMPS forecasts are more statically stable in the median across all wind speeds (Fig. 4), indicating 
Avg
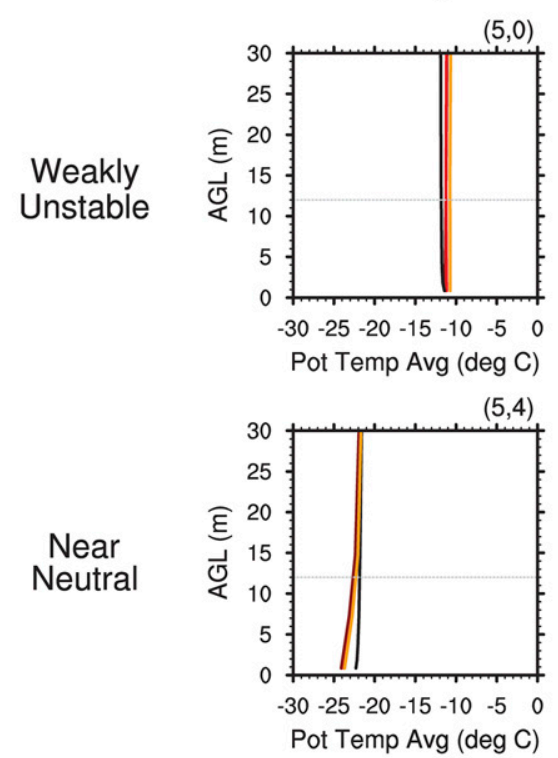

Near Neutral

Moderately Stable
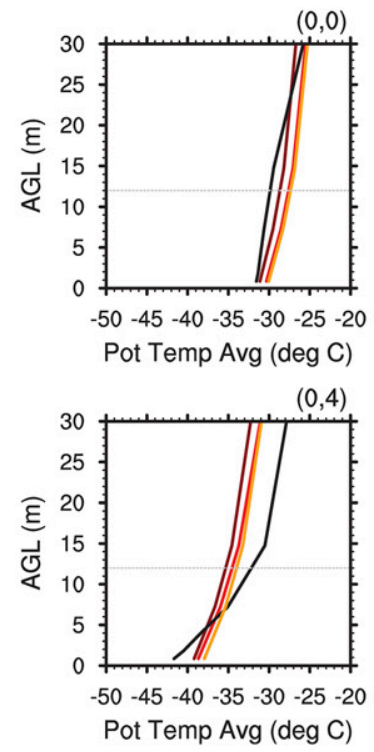

Bias

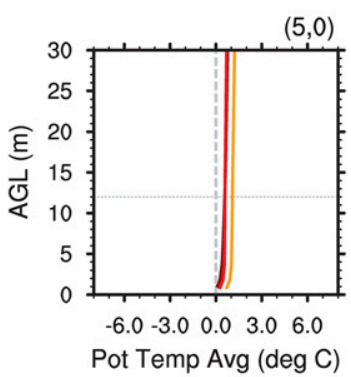

$(5,4)$
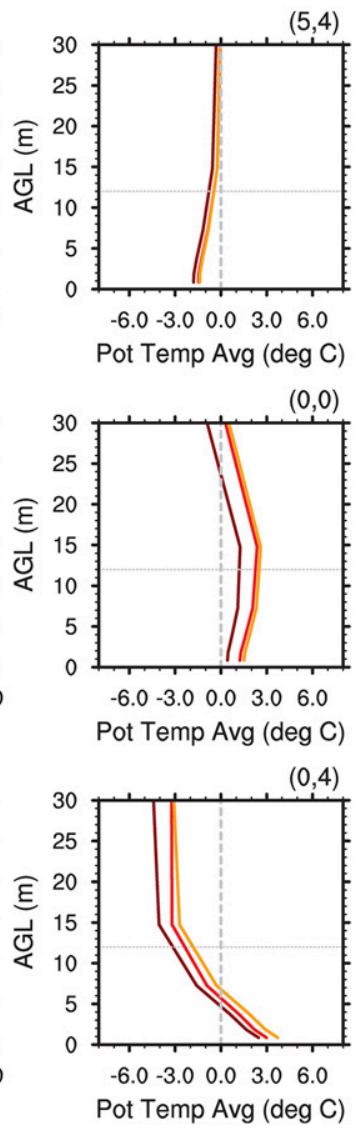

RMSE



$(5,4)$
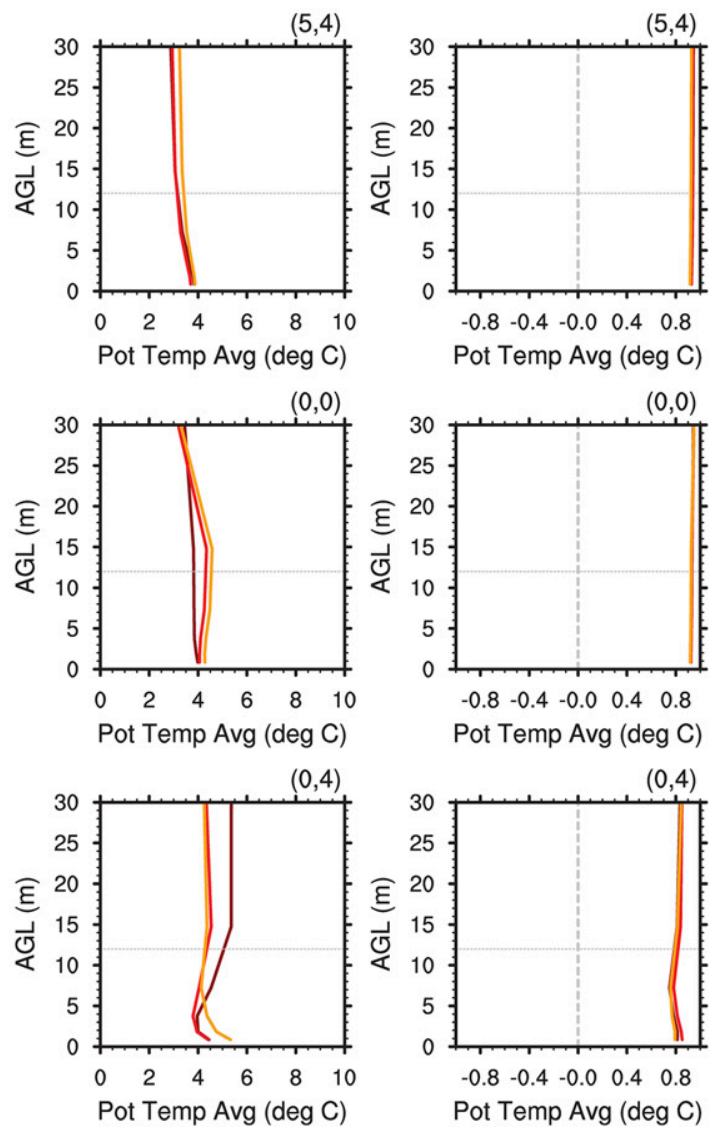

Corr

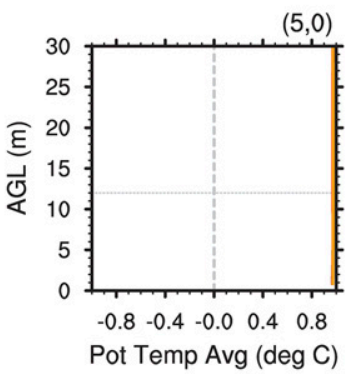

$(5,4)$



FIG. 12. As in Fig. 11, but for potential temperature.

AMPS's behavior differs from what has been noted previously in the literature (Derbyshire 1999; Poulos and Burns 2003; Tjernstrom et al. 2004; Holtslag 2006; Rinke et al. 2012; Holtslag et al. 2013; Wille et al. 2016). This indicates that in the median AMPS either does not have enough mechanical mixing for a given wind speed, has a negative radiation bias, or has some combination of these two mechanisms. Additionally, in the 10th and 90th percentiles there seems to be a possible change in the model bias from too little mixing under conditions of light winds and surface heating, resulting in more unstable conditions than are observed, to too much mechanical mixing under conditions of light winds and surface cooling, resulting in less stable conditions than are observed.

The SOM method is used to identify the potential temperature anomaly patterns observed at Tall Tower (Fig. 2) and to evaluate the performance of AMPS across patterns with varying degrees of static stability. The results indicate the model errors do vary as a function of static stability. For the weakly unstable SOM pattern $(5,0)$, AMPS has a negative wind speed bias near the surface (Figs. 8 and 9), resulting in weaker mechanical mixing, which under surface heating conditions 
leads to a surface warm bias (Fig. 10) and a negative stability bias (Fig. 7). For the near-neutral SOM patterns on the right side of the SOM (with the exception of the top-right pattern), AMPS has a negative wind speed bias (Figs. 8 and 9) resulting in weaker mechanical mixing, which under surface cooling conditions creates a surface cold bias (Fig. 10) and a positive stability bias (Fig. 7). This is consistent with the findings of Steinhoff et al. (2009), who also analyzed the ability of AMPS to forecast static stability. The SOM analysis of model error statistics as a function of forecast hour provided additional insight into the potential causes of the positive stability bias in AMPS. The model error statistics for the near-neutral pattern $(5,4)$ show a decrease in the nearsurface wind speed bias and RMSE as a function of forecast hour (Fig. 11), but this does not correspond to a change in the surface potential temperature bias and RMSE over forecast hour (Fig. 12). This suggests some of the surface cold bias may be driven by a negative radiation bias in AMPS rather than simply by a mixing bias induced by the wind speed bias.

For the stable SOM patterns (columns 0-3), AMPS has a consistent positive near-surface wind speed bias (Figs. 8 and 9). The patterns range from a surface warm bias in the most stable patterns (columns 0 and 1 ) to a surface cold bias in the moderately stable patterns (column 3) (Fig. 10). The most stable patterns have a negative stability bias and the moderately stable patterns have a positive stability bias (Fig. 7) with column 2 showing a mix of positive and negative stability biases. For the most stable patterns the positive wind speed bias results in more mechanical mixing, which is consistent with the modeled surface warm bias (Fig. 9) and negative stability bias (Fig. 7). This is consistent with the literature, which states that a positive wind speed bias results in a negative stability bias (Tjernstrom et al. 2004; Wille et al. 2016). The patterns with a surface cold bias (Fig. 10) must have a negative radiation bias to compensate for the additional mixing from the positive nearsurface wind speed bias (Figs. 8 and 9). The range of model errors identified within the group of statically stable patterns illustrates the ability of the SOM method to provide details about the model performance as a function of static stability.

Analysis of model errors (bias, RMSE, and correlation) as a function of stability (Figs. 11 and 12) indicate that model errors increase with increasing stability (moving from the top to the bottom of these figures), consistent with the fact that models have difficulty in simulating stable boundary layer conditions (Derbyshire 1999; Poulos and Burns 2003; Tjernstrom et al. 2004; Brunke et al. 2006; Holtslag 2006; Steeneveld et al. 2006; Banta et al. 2007; Teixeira et al. 2008; Baklanov et al. 2011; Atlaskin and
Vihma 2012; Rinke et al. 2012; Holtslag et al. 2013; Kleczek et al. 2014; Sterk et al. 2015). Figures 11 and 12 also indicate model errors do not uniformly increase with increased forecast duration, as might be expected. Instead, wind speed errors were found to decrease with increasing forecast time for the near-neutral patterns $(5,4)$ and were nearly constant as a function of forecast time for the weakly unstable patterns $(5,0)$ (Fig. 11), indicating the model errors vary as a function of stability and demonstrating the utility of SOMs for this analysis.

Future work by the authors will include an evaluation of the full depth of the boundary layer in AMPS using observations from the Small Unmanned Meteorological Observer (SUMO; Cassano 2014). The SUMO was used to make observations of the diurnal cycle of the summertime boundary layer, with a time resolution of the order of hours, at the location of Tall Tower during January 2014. This dataset will allow us to assess the ability of AMPS to replicate the diurnal evolution of the boundary layer over the RIS.

Acknowledgments. We thank Linda Keller, David Mikolajczyk, Jonathan Thom, George Weidner, and Lee Welhouse from the University of Wisconsin-Madison for help with the Tall Tower AWS. This work was funded by NSF Grants ANT-0943952, ANT-0944018, ANT-1245663, and ANT-1245737, as well as UCAR AMPS Grant GRT 0032749. We thank the three reviewers for their comments, which were used to improve this manuscript.

\section{REFERENCES}

Atlaskin, E., and T. Vihma, 2012: Evaluation of NWP results for wintertime nocturnal boundary-layer temperatures over Europe and Finland. Quart. J. Roy. Meteor. Soc., 138, 1440-1451, doi:10.1002/qj.1885.

Baklanov, B. G., R. Bornstein, L. Mahrt, S. S. Zilitnkevich, P. Taylor, S. E. Larsen, M. W. Rotach, and H. J. S. Fernando, 2011: The nature, theory, and modeling of atmospheric planetary boundary layers. Bull. Amer. Meteor. Soc., 92, 123-128, doi:10.1175/2010BAMS2797.1.

Banta, R. M., L. Mahrt, D. Vickers, J. Sun, B. B. Balsley, Y. L. Pichugina, and E. J. Williams, 2007: The very stable boundary layer on nights with weak low-level jets. J. Atmos. Sci., 64 , 3068-3090, doi:10.1175/JAS4002.1.

Bromwich, D. H., A. J. Monaghan, K. W. Manning, and J. G. Powers, 2005: Real-time forecasting for the Antarctic: An evaluation of the Antarctic Mesoscale Prediction System (AMPS). Mon. Wea. Rev., 133, 579-603, doi:10.1175/MWR-2881.1.

_, K. M. Hines, and L.-S. Bai, 2009: Development and testing of Polar WRF: 2. Arctic Ocean. J. Geophys. Res., 114, D08122, doi:10.1029/2008JD010300.

— , D. F. Steinhoff, I. Simmonds, K. Keay, and R. L. Fogt, 2011: Climatological aspects of cyclogenesis near Adélie Land Antarctica. Tellus, 63A, 921-938, doi:10.1111/j.1600-0870.2011.00537.x.

_ , F. O. Otieno, K. M. Hines, K. W. Manning, and E. Shilo, 2013: Comprehensive evaluation of Polar Weather Research 
and Forecasting performance in the Antarctic. J. Geophys. Res. Atmos., 118, 274-292, doi:10.1029/2012JD018139.

Brunke, M. A., M. Zhou, X. Zeng, and E. L Andreas, 2006: An intercomparison of bulk aerodynamic algorithms used over sea ice with data from the Surface Heat Budget for the Arctic Ocean (SHEBA) experiment. J. Geophys. Res., 111, C09001, doi:10.1029/2005JC002907.

Cassano, E. N., J. J. Cassano, and M. Nolan, 2011: Synoptic weather pattern controls on temperature in Alaska. J. Geophys. Res., 116, D11108, doi:10.1029/2010JD015341.

Cassano, J. J., 2014: Observations of atmospheric boundary layer boundary layer temperature profiles with a small unmanned aerial vehicle. Antarct. Sci., 26, 205-213, doi:10.1017/ S0954102013000539.

_, M. A. Nigro, and M. A. Lazzara, 2016: Characteristics of the nearsurface atmosphere over the Ross Ice Shelf, Antarctica. J. Geophys. Res. Atmos., 121, 3339-3362, doi:10.1002/2015JD024383.

Chen, F., and J. Dudhia, 2001: Coupling an advanced land surfacehydrology model with the Penn State-NCAR MM5 modeling system. Part I: Model description and implementation. Mon. Wea. Rev., 129, 569-585, doi:10.1175/1520-0493(2001)129<0569: CAALSH $>2.0 . \mathrm{CO} ; 2$.

Chou, M.-D., and M. J. Suarez, 1994: An efficient thermal infrared radiation parameterization for use in general circulation models. NASA Tech. Memo. 104606, Vol. 3, 85 pp. [Available online at https://ntrs.nasa.gov/search.jsp? $\mathrm{R}=19950009331$.]

Derbyshire, S., 1999: Stable boundary-layer modeling: Establishing approaches and beyond. Bound.-Layer Meteor., 90, 423-446, doi:10.1023/A:1001749007836.

DuVivier, A. K., J. J. Cassano, A. P. Craig, J. Hamman, W. Maslowski, B. Nijssen, R. Osinski, and A. Roberts, 2016: Atmospheric forcing and oceanic response during strong wind events around southeastern Greenland as modeled over 20 winters in the Regional Arctic System Model (RASM). J. Climate, 29, 975-994, doi:10.1175/JCLI-D-15-0592.1.

Genthon, C., D. Six, V. Favier, M. Lazzara, and L. Keller, 2011: Atmospheric temperature measurement biases on the Antarctic Plateau. J. Atmos. Oceanic Technol., 28, 1598-1605, doi:10.1175/JTECH-D-11-00095.1.

,-- H. Gallee, P. Grigioni, and A. Pellegrini, 2013: Two years of atmospheric boundary layer observations on a $45-\mathrm{m}$ tower at Dome C on the Antarctic plateau. J. Geophys. Res. Atmos., 118, 3218-3232, doi:10.1002/jgrd.50128.

Higgins, M. E., and J. J. Cassano, 2010: Response of Arctic $1000 \mathrm{hPa}$ circulation to changes in horizontal resolution and sea ice forcing in the Community Atmospheric Model. J. Geophys. Res., 115, D17114, doi:10.1029/2009JD013440.

Hines, K. M., and D. H. Bromwich, 2008: Development and testing of Polar WRF. Part I: Greenland Ice Sheet meteorology. Mon. Wea. Rev., 136, 1971-1989, doi:10.1175/2007MWR2112.1.

,-- L.-S. Bai, M. Barlage, and A. G. Slater, 2011: Development and testing of Polar WRF. Part III: Arctic land. J. Climate, 24, 26-48, doi:10.1175/2010JCLI3460.1.

,,--- C. M. Bitz, J. G. Powers, and K. W. Manning, 2015: Sea ice enhancements to Polar WRF. Mon. Wea. Rev., 143, 2363-2385, doi:10.1175/MWR-D-14-00344.1.

Holtslag, A. A. M., 2006: GEWEX Atmospheric Boundary-Layer Study (GABLS) on stable boundary layers. Bound.-Layer Meteor., 118, 243-246, doi:10.1007/s10546-005-9008-6.

, and Coauthors, 2013: Stable atmospheric boundary layers and diurnal cycles: Challenges for weather and climate models. Bull. Amer. Meteor. Soc., 94, 1691-1706, doi:10.1175/ BAMS-D-11-00187.1.
Hong, S.-Y., and J.-O. J. Lim, 2006: The WRF single-moment 6-class microphysics scheme (WSM6). J. Korean Meteor. Soc., 42, 129-151.

— J. Dudhia, and S.-H. Chen, 2004: A revised approach to ice microphysical processes for the bulk parameterization of clouds and precipitation. Mon. Wea. Rev., 132, 103-120, doi:10.1175/1520-0493(2004)132<0103:ARATIM>2.0.CO;2.

$\mathrm{Hu}$, Y., and Coauthors, 2014: Meteorological data for the astronomical site at Dome A, Antarctica. Publ. Astron. Soc. Pac., 126, 868-881, doi:10.1086/678327.

Hudson, S. R., and R. E. Brandt, 2005: A look at the surface-based temperature inversion on the Antarctic Plateau. J. Climate, 18, 1673-1696, doi:10.1175/JCLI3360.1.

Janjić, Z. I., 1990: The step-mountain coordinate: Physical package. Mon. Wea. Rev., 118, 1429-1443, doi:10.1175/1520-0493(1990)118<1429: TSMCPP $>2.0 . \mathrm{CO} ; 2$.

— 1996: The surface layer in the NCEP Eta Model. Preprints, 11th Conf. on Numerical Weather Prediction, Norfolk, VA, Amer. Meteor. Soc., 354-355.

_ 2002: Nonsingular implementation of the Mellor-Yamada level 2.5 scheme in the NCEP Meso model. NCEP Office Note 437, $61 \mathrm{pp}$. [Available online at http://www.emc.ncep.noaa. gov/officenotes/newernotes/on437.pdf.]

Kain, J. S., 2004: The Kain-Fritsch convective parameterization: An update. J. Appl. Meteor., 43, 170-181, doi:10.1175/ 1520-0450(2004)043<0170:TKCPAU > 2.0.CO;2.

King, J. C., and J. Turner, 1997: Antarctic Meteorology and Climatology. Cambridge University Press, 409 pp.

Kleczek, M. A., G. Steeneveld, and A. A. M. Holtslag, 2014: Evaluation of the Weather Research and Forecasting mesoscale model for GABLS3: Impact of boundary-layer schemes, boundary conditions and spin-up. Bound.-Layer Meteor., 152, 213-243, doi:10.1007/s10546-014-9925-3.

Kohonen, T., 2001: Self-Organizing Maps. 3rd ed. Springer, 501 pp. Lazzara, M. A., G. A. Weidner, L. M. Keller, J. E. Thom, and J. J. Cassano, 2012: Antarctic Automatic Weather Station program: 30 years of polar observations. Bull. Amer. Meteor. Soc., 93, 1519-1537, doi:10.1175/BAMS-D-11.00015.1.

Mlawer, E. J., S. J. Taubman, P. D. Brown, M. J. Iacono, and S. A. Clough, 1997: Radiative transfer for inhomogeneous atmosphere: RRTM, a validated correlated-k model for the longwave. J. Geophys. Res., 102, 16 663-16 682, doi:10.1029/97JD00237.

Monin, A. S., and A. M. Obukhov, 1954: Basic laws of turbulent mixing in the surface layer of the atmosphere. Contrib. Geophys. Inst. Acad. Sci., 151, 163-187.

Nicolas, J. P., and D. H. Bromwich, 2011: Climate of West Antarctica and influence of marine air intrusions. J. Climate, 24, 49-67, doi:10.1175/2010JCLI3522.1.

Nigro, M. A., and J. J. Cassano, 2014a: Analysis of the Ross Ice Shelf airstream forcing mechanisms using self-organizing maps. Mon. Wea. Rev., 142, 4719-4734, doi:10.1175/MWR-D-14-00077.1. , and,$- 2014 \mathrm{~b}$ : Identification of surface wind patterns over the Ross Ice Shelf, Antarctica, using self-organizing maps. Mon. Wea. Rev., 142, 2361-2378, doi:10.1175/MWR-D-13-00382.1.

- _ — , and M. W. Seefeldt, 2011: A weather-pattern-based approach to evaluate the Antarctic Mesoscale Prediction System (AMPS) forecasts: Comparison to automatic weather station observations. Wea. Forecasting, 26, 184-198, doi:10.1175/ 2010WAF2222444.1.

,,-- M. A. Lazzara, and L. M. Keller, 2012: Case study of a barrier wind corner jet off the coast of the Prince Olav Mountains, Antarctica. Mon. Wea. Rev., 140, 2044-2063, doi:10.1175/ MWR-D-11-00261.1. 
Parish, T. R., J. J. Cassano, and M. W. Seefeldt, 2006: Characteristics of the Ross Ice Shelf air stream. J. Geophys. Res., 111, D12109, doi:10.1029/2005JD006185.

Poulos, G. S., and S. P. Burns, 2003: An evaluation of bulk Ri-based surface layer flux formulas for stable and very stable conditions with intermittent turbulence. J. Atmos. Sci., 60, 2523-2537, doi:10.1175/1520-0469(2003)060<2523:AEOBRS>2.0.CO;2.

Powers, J. G., K. W. Manning, D. H. Bromwich, J. J. Cassano, and A. M. Cayette, 2012: A decade of Antarctic science support through AMPS. Bull. Amer. Meteor. Soc., 93, 1699-1712, doi:10.1175/BAMS-D-11-00186.1.

Reusch, D. B., R. B. Alley, and B. C. Hewitson, 2005: Relative performance of self-organizing maps and principal component analysis in pattern extraction from synthetic climatological data. Polar Geogr., 29, 188-212, doi:10.1080/789610199.

Rinke, A., Y. Ma, L. Bian, Y. Xin, K. Dethloff, P. O. G. Persson, C. Lupkes, and C. Xiao, 2012: Evaluation of atmospheric boundary layer-surface process relationships in a regional climate model along an East Antarctic traverse. J. Geophys. Res., 117, D09121, doi:10.1029/2011JD016441.

Riordan, A. J., 1977: Variations of temperature and air motion in the 0- to 32-meter layer at Plateau Station, Antarctica. Meteorological Studies at Plateau Station, Antarctica, J. A. Businger, Ed., Antarctic Research Series, Vol. 25, Amer. Geophys. Union, 113-127.

Schlosser, E. M., G. Duda, J. G. Powers, and K. W. Manning, 2008: Precipitation regime of Dronning Maud Land, Antarctica, derived from Antarctic Mesoscale Prediction System (AMPS) archive data. J. Geophys. Res., 113, D24108, doi:10.1029/ 2008JD009968.

Schuenemann, K., and J. J. Cassano, 2010: Changes in synoptic weather patterns and Greenland precipitation in the 20th and 21st centuries. Part 2: Analysis of 21st century atmospheric changes using self-organizing maps. J. Geophys. Res., 115, D05108, doi:10.1029/2009JD011706.

Seefeldt, M. W., and J. J. Cassano, 2008: An analysis of low-level jets in the greater Ross Ice Shelf region based on numerical simulations. Mon. Wea. Rev., 136, 4188-4205, doi:10.1175/ 2008MWR2455.1.
, and - 2012: A description of the Ross Ice Shelf air stream (RAS) through the use of self-organizing maps (SOMs). J. Geophys. Res., 117, D09112, doi:10.1029/2011JD016857.

,-- , and T. R. Parish, 2007: An analysis of the Ross Ice Shelf surface wind field, during the austral autumn, based on dominant wind regimes. J. Appl. Meteor., 46, 1933-1955, doi:10.1175/2007JAMC1442.1.

Speirs, J. C., D. F. Steinhoff, H. A. McGrowan, D. H. Bromwich, and A. J. Monaghan, 2010: Foehn winds in the McMurdo Dry Valleys, Antarctica: The origin of extreme warming events. J. Climate, 23, 3577-3598, doi:10.1175/2010JCLI3382.1.

Steeneveld, G. J., B. J. H. Van De Wiel, and A. A. M. Holtslag, 2006: Modelling the Arctic stable boundary layer and its coupling to the surface. Bound.-Layer Meteor., 118, 357-378, doi:10.1007/s10546-005-7771-z.

Steinhoff, D. F., S. Chaudhuri, and D. H. Bromwich, 2009: A case study of a Ross Ice Shelf airstream event: A new perspective. Mon. Wea. Rev., 137, 4030-4046, doi:10.1175/2009MWR2880.1.

Sterk, H. A. M., G. J. Steeneveld, T. Vihma, P. S. Anderson, F. C. Bosveld, and A. A. M. Holtslag, 2015: Clear-sky stable boundary layers with low winds over snow-covered surfaces. Part 1: WRF model evaluation. Quart. J. Roy. Meteor. Soc., 141, 2165-2184, doi:10.1002/qj.2513.

Teixeira, J., and Coauthors, 2008: Parameterization of the atmospheric boundary layer. Bull. Amer. Meteor. Soc., 89, 453-458, doi:10.1175/BAMS-89-4-453.

Tjernstrom, M., and Coauthors, 2004: Modeling the Arctic boundary layer: An evaluation of six ARCMIP regional-scale models using data from the SHEBA project. Bound.-Layer Meteor., 117, 337-381, doi:10.1007/s10546-004-7954-z.

Valkonen, T., T. Vihma, M. M. Johansson, and J. Launiainen, 2014: Atmosphere-sea ice interaction in early summer in the Antarctic: Evaluation and challenges of a regional atmospheric model. Quart. J. Roy. Meteor. Soc., 140, 1536-1551, doi:10.1002/qj.2237.

Wille, J. D., D. H. Bromwich, M. A. Nigro, J. J. Cassano, M. Mateling, and M. A. Lazzara, 2016: Evaluation of the AMPS boundary layer simulations on the Ross Ice Shelf with tower observations. J. Appl. Meteor. Climatol., 55, 2349-2367, doi:10.1175/JAMC-D-16-0032.1. 